\title{
Evaluation of ASSERT-PV V3R1 against the PSBT Benchmark
}

\author{
Kenneth H. Leung and David R. Novog \\ Department of Engineering Physics, McMaster University, 1280 Main Street West, Hamilton, ON, Canada L8S 4L7 \\ Correspondence should be addressed to Kenneth H. Leung, leungk4@mcmaster.ca
}

Received 7 July 2012; Accepted 18 September 2012

Academic Editor: Alessandro Petruzzi

Copyright ( 12012 K. H. Leung and D. R. Novog. This is an open access article distributed under the Creative Commons Attribution License, which permits unrestricted use, distribution, and reproduction in any medium, provided the original work is properly cited.

\begin{abstract}
Void fraction and DNB calculations conducted using ASSERT-PV V3R1 are evaluated against data from the NUPEC database as part of the OECD/NEA Pressurized Water Reactor Subchannel Benchmark Tests (PSBT). Void fraction measurements were well represented in the isolated single subchannel cases, with $77.0 \%$ of all predicted values falling within $\pm 2 \sigma_{\exp }=0.06$ of the experimental value. In the B5 type bundle, an average void fraction error of $\bar{\epsilon}_{\alpha}=-0.0540$ was reported at the lower elevation, while this value was $\bar{\epsilon}_{\alpha}=-0.0405$ at the upper measurement location. ASSERT was able to predict the steady state DNB power of the bundles to within $\pm 10 \%$ of the measured value for a total of 344 times out of 432 . Sensitivity studies conducted indicate that the Ahmad correlation with the Groeneveld 1995 CHF lookup table yielded the most accurate results, although some data points fell within the limiting quality region where the accuracy was reduced.
\end{abstract}

\section{Introduction}

The prediction of both the void fraction distribution in a rod bundle and the power at which the departure from nucleate boiling (DNB) occurs is an ongoing area of study in the field of thermalhydraulics. To that end, data from tests conducted by the Japanese NUPEC corporation have been released to the international community as part of a benchmark sponsored by the Organization of Economic Cooperation and Development's Nuclear Energy Agency (OECD/NEA). The overarching objective of the Pressurized Water Reactor (PWR) Subchannel Bundle Tests (PSBT) is to assess the current capabilities of both subchannel and Computational Fluid Dynamics (CFD) codes in predicting the void fraction and DNB powers under both steady state and transient conditions [1].

In this study, the Advanced Solution of Subchannel Equations in Reactor Thermalhydraulics (ASSERT) code is evaluated against the benchmark database. ASSERT-PV is a Canadian code developed and maintained by Atomic Energy of Canada Limited (AECL) in support of activities involving fuel design and safety analysis in the Canadian nuclear industry. This code models the behavior of the coolant at the subchannel level and specializes in representing conditions found in Pressurized Heavy Water Reactors (PHWR). Subchannel codes can represent the fluid conditions at a higher spatial resolution than is typically found in system codes, and utilize empirical relationships developed to model phenomena which occur specifically in rod bundle geometries. However, effects such as inter-subchannel turbulent mixing and DNB are not yet fully understood, and so comparisons of code predictions to datasets are part of an ongoing effort to improve the accuracy of the codes.

\section{Facility}

The facility used for these experiments was designed to represent conditions which would be found in a typical PWR, and key characteristics are listed in Table 1. Two types of experiments are simulated in this study: isolated single subchannel experiments and rod bundle experiments.

2.1. Subchannel Test Sections. The single subchannel experiments consisted of test sections with cross-sectional shapes identical to what would be found in a bundle. Four geometries were examined corresponding to a typical, thimble, side, and corner subchannel, and these are illustrated in Figure 1. Each test section was $1.4 \mathrm{~m}$ in length, and electrically heated 
TABLE 1: Summary of facility [1].

\begin{tabular}{lc}
\hline Parameter & Range \\
\hline Pressure $(\mathrm{MPa})$ & $4.9-16.6$ \\
Mass flux $\left(\mathrm{Mg} / \mathrm{m}^{2} \mathrm{~s}\right)$ & $0.55-4.15$ \\
Inlet temperature $\left({ }^{\circ} \mathrm{C}\right)$ & $140.0-345.0$ \\
\hline
\end{tabular}

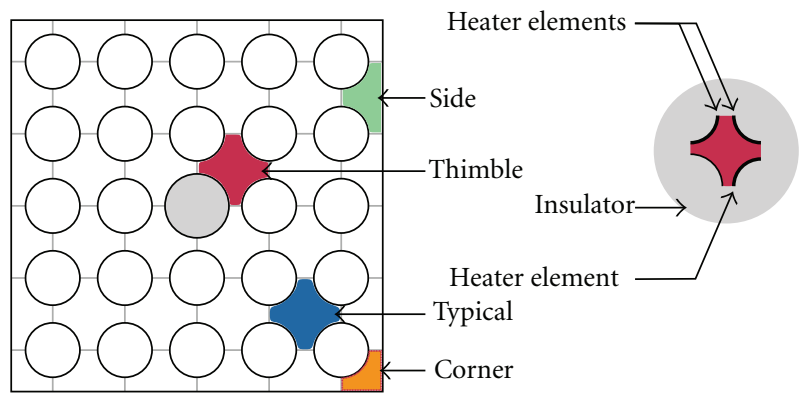

FIGURE 1: Isolated subchannel geometry types (left) and crosssection of the central type test section (right) [1].

along the walls corresponding to where the surface of a rod would be located. The fluid density was measured at the top of test section using gamma densitometry, and the void fraction was deduced from this value.

2.2. Test Bundles. The bundle experiments were conducted using $5 \times 5$ and $6 \times 6$ arrays of electrically heated rods in several different configurations as listed in Table 2. The bundles are designed to represent a portion of a full height $(3658 \mathrm{~mm}) 17 \times 17$ PWR assembly and are supported by mixing vanes and spacer grids. Each rod consisted of an inconel 600 heater surrounding an insulator made of alumina. Gamma densitometry was used to measure the void fraction at three elevations: 2216, 2669, and $3177 \mathrm{~mm}$ above the start of the heated section, while the DNB point was determined by monitoring the surface temperature of the rods using thermocouples.

Each of the bundle configurations used different radial and axial power profiles and had a different number of mixing vanes and spacer grids. The void fraction tests were conducted on bundle configurations $\mathrm{B} 5, \mathrm{~B} 6$, and $\mathrm{B} 7$ while the DNB tests were conducted on bundles $\mathrm{A} 0, \mathrm{~A} 2, \mathrm{~A} 3, \mathrm{~A} 4$, A8, A11, and A12. Bundle A1 was used for the subchannel fluid temperature distribution tests. In some cases, the same bundle arrangement was used in both the void fraction and DNB tests, and this is indicated in Table 2 with some configurations having multiple names.

In the void fraction and DNB tests, the rods on the periphery of the bundle were operated at a lower power than those in the central portion of the bundle as illustrated in Figure 2. In several configurations (B7, A8, and A12) the central rod in the bundle was replaced by an unheated thimble rod. In the fluid temperature tests, an asymmetric power distribution was used.

A series of transient tests were also run using these bundles, simulating scenarios involving a power increase, system depressurization, flow rate reduction, and inlet temperature increase.

\section{Code Description}

ASSERT is an unequal-velocity unequal-temperature (UVUT) code which solves a set of equations governing the conservation of mass, momentum, and energy. The code utilizes a drift-flux model to represent the relative velocities between the liquid and vapour phases, while a set of closure relationships are used to represent the phenomena such as friction, heat transfer, and turbulent mixing.

3.1. Constitutive Equations. The equations governing the conservation and transport of mass, axial and lateral momentum, and mixture enthalpy are listed in (1), (2), (3), and (4). Although only the equation governing the mixture enthalpy is supplied in (4), the liquid and vapour enthalpies are solved similarly. The drift velocity in the axial direction is supplied in (5), with the relative vapour velocity being defined in a similar manner.

$$
\begin{gathered}
A \Delta x \frac{\partial \rho}{\partial t}+A \Delta x \frac{\partial}{\partial x}(\rho u)+\sum_{k} W_{k}=0, \\
A \Delta x \frac{\partial}{\partial t}(\rho u)+A \Delta x \frac{\partial}{\partial x}\left(\rho_{f} u_{f} u_{f}+\rho_{g} u_{g} u_{g}\right) \\
=-A \Delta x \frac{\partial p}{\partial x}-\sum_{k}\left[\left(W_{f} u_{f}+W_{g} u_{g}\right)\right]_{k} \\
+\sum_{k}\left(W_{f}^{\prime} \Delta u_{f}+W_{g}^{\prime} \Delta u_{g}\right)_{k} \\
-F_{\text {frict }}+\rho A \Delta x g_{x}, \\
A \Delta x \frac{\partial}{\partial t}(\rho v)+A \Delta x \frac{\partial}{\partial x}(\rho u v)-v A \Delta x \frac{\partial}{\partial x}(\rho u) \\
=-A \Delta x \frac{\partial p}{\partial y}-F_{\text {frict }} \\
+\frac{\partial}{\partial x}\left(A \Delta x \frac{w_{f}^{\prime} \Delta u_{f}+w_{g}^{\prime} \Delta u_{g}}{S \Delta x}\right) \\
+\rho A \Delta x g_{y}, \\
\Delta x A \rho \frac{\partial h}{\partial t}+\Delta x A \frac{\left(\rho_{f} u_{f} h_{f}+\rho_{g} u_{g} h_{g}\right)}{\partial x} \\
-\Delta x A h\left(\frac{\partial \rho_{f} u_{f}}{\partial x}+\frac{\partial \rho_{g} u_{g}}{\partial x}\right) \\
+\sum_{k}\left[\left(W_{f} h_{f}\right)+\left(W_{g} h_{g}\right)\right]_{k}-h \sum_{k}(W)_{k} \\
-\sum_{k}\left[\left(W_{f}^{\prime} \Delta h_{f}+W_{g}^{\prime} \Delta h_{g}\right)\right]_{k}-q=0 \\
u_{r}=u_{g}-u_{f}, \\
u_{g}=u+\frac{(\alpha \rho)_{g}}{\rho} u_{r}, \\
\rho
\end{gathered}
$$




\begin{tabular}{|c|c|c|c|c|}
\hline 0.85 & 0.85 & 0.85 & 0.85 & 0.85 \\
\hline 0.85 & 1 & 1 & 1 & 0.85 \\
\hline 0.85 & 1 & 1 & 1 & 0.85 \\
\hline 0.85 & 1 & 1 & 1 & 0.85 \\
\hline 0.85 & 0.85 & 0.85 & 0.85 & 0.85 \\
\hline
\end{tabular}

(a)

\begin{tabular}{|c|c|c|c|c|}
\hline 0.85 & 0.85 & 0.85 & 0.85 & 0.85 \\
\hline 0.85 & 1 & 1 & 1 & 0.85 \\
\hline 0.85 & 1 & & 1 & 0.85 \\
\hline 0.85 & 1 & 1 & 1 & 0.85 \\
\hline 0.85 & 0.85 & 0.85 & 0.85 & 0.85 \\
\hline
\end{tabular}

(b)

\begin{tabular}{|c|c|c|c|c|}
\hline 1 & 1 & 0.25 & 0.25 & 0.25 \\
\hline 1 & 1 & 1 & 0.25 & 0.25 \\
\hline 1 & 1 & 0.25 & 0.25 & 0.25 \\
\hline 1 & 1 & 1 & 0.25 & 0.25 \\
\hline 1 & 1 & 0.25 & 0.25 & 0.25 \\
\hline
\end{tabular}

(c)

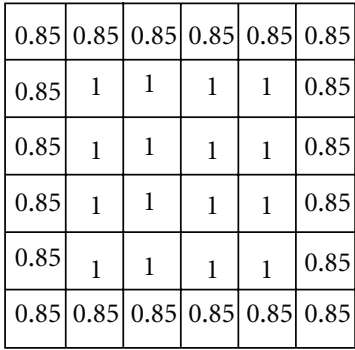

(d)

Figure 2: Radial power profiles used in the experiments [1].

TABLE 2: Bundle parameters [1].

\begin{tabular}{lcccccc}
\hline Parameter & B5, B8, A2 & B6, A4, A11 & B7, A8, A12 & A0 & A3 & A1 \\
\hline Configuration & $5 \times 5$ & $5 \times 5$ & $5 \times 5$ & $5 \times 5$ & $6 \times 6$ & $5 \times 5$ \\
Heated rods & 25 & 25 & 24 & 25 & 36 & 25 \\
Thimble rods & 0 & 0 & 1 & 0 & 0 & 0 \\
Rod diameter (mm) & 9.5 & 9.5 & 9.5 & 9.5 & 9.5 & 9.5 \\
Thimble diam (mm) & - & - & 12.24 & - & - & - \\
Rod pitch (mm) & 12.6 & 12.6 & 12.6 & 12.6 & 12.6 & 12.6 \\
Heated length (mm) & 3658 & 3658 & 3658 & 3658 & 3658 & 3658 \\
Radial power profile & $\mathrm{A}$ & $\mathrm{A}$ & $\mathrm{B}$ & $\mathrm{A}$ & $\mathrm{D}$ & $\mathrm{C}$ \\
Axial power shape & Uniform & Cosine & Cosine & Uniform & Uniform & Uniform \\
Number of MVs & 7 & 7 & 7 & 5 & 7 & 7 \\
Number of NMVs & 2 & 2 & 2 & 2 & 2 & 2 \\
Number of SSs & 8 & 8 & 8 & 6 & 8 & 8 \\
\hline
\end{tabular}

3.2. Friction. The turbulent wall friction factor is represented in ASSERT using an implicit approximation to ColebrookWhite which is shown in (6). This correlation is valid up until the onset of significant void (OSV), beyond which a two-phase multiplier is applied to represent the additional pressure drop caused by the presence of the vapour. In this study the Friedel correlation (7) was selected for its applicability to the range of conditions being simulated. One has

$$
\begin{gathered}
f=\left[-2 \log \left(\frac{\delta d_{\text {hyd }}}{3.7}+\frac{2.51}{\operatorname{Re} \sqrt{f}}\right)\right]^{-2}, \\
\Phi_{2}=A_{1}+\frac{3.24 A_{2} A_{3}}{\mathrm{Fr}^{0.0454} \mathrm{We}^{0.035}}, \\
A_{1}=(1-X)^{2}+X^{2}\left(\frac{\rho_{f} f_{g, \text { only }}}{\rho_{g} f_{f, \text { only }}}\right), \\
A_{2}=X^{0.78}(1-X)^{0.224}, \\
A_{3}=\left(\frac{\rho_{f}}{\rho_{g}}\right)^{0.91}\left(\frac{\mu_{g}}{\mu_{l}}\right)^{0.19}\left(1-\frac{\mu_{g}}{\mu_{l}}\right)^{0.7} .
\end{gathered}
$$

3.3. Heat Transfer. ASSERT distributes the heat from the rods to either the fluid, vapour, or bubble nucleation. Under single-phase conditions, the heat transfer between the wall and the fluid is governed by the Dittus-Boelter correlation in (8) for a fluid subjected to heating.

$$
H_{\text {Dittus }}=\frac{K_{f}}{d_{\text {hyd }}} 0.023 \operatorname{Re}^{4 / 5} \operatorname{Pr}^{2 / 5} .
$$

As the fluid is heated towards its saturation temperature, vapour bubbles will begin to nucleate on the rod walls and ASSERT switches to the Ahmad correlation to represent the two-phase heat transfer. The assumption is that the heat flux from the wall goes either into raising the bulk fluid temperature or creating bubbles [2]. The Ahmad correlation was selected since it covered the widest range of pressures, although it should be noted that the some of the cases in the PSBT database exceed the recommended pressure and mass flux conditions of

$$
H_{\text {Ahmad }}=2.44 \frac{K_{f}}{d_{\text {hyd }}} \operatorname{Re}^{1 / 2} \operatorname{Pr}^{1 / 3}\left(\frac{h_{\text {inlet }}}{h_{f}}\right)^{1 / 3}\left(\frac{h_{f g}}{h_{f}}\right)^{1 / 3} .
$$

This correlation is activated when the bulk fluid temperature in the node is beyond the onset of significant void (OSV) point given by

$$
\left(T_{\text {sat }}-T_{f}\right)_{\text {Osv }}=\frac{q^{\prime \prime}}{H_{\text {Ahmad }}} .
$$

3.3.1. Departure from Nucleate Boiling. At the end of each iteration, each node in ASSERT is checked to determine 
the margin remaining to the critical heat flux $(\mathrm{CHF})$. The value for the CHF is ascertained by checking the mass flux, pressure, and quality at each node against the 1995 CHF lookup table by Groeneveld et al. [3]. This lookup table was created using data for $8 \mathrm{~mm}$ tubes, and so correction factors accounting for the subchannel hydraulic diameter $\left(F_{\mathrm{CHF}, \text { size }}\right)$ and the rod to rod gap distance $\left(F_{\mathrm{CHF}, \mathrm{gap}}\right)$ are applied. The term $K_{X}$ in (13) is a quality correction factor built into $F_{\text {CHF,gap. }}$ One has

$$
\begin{gathered}
q_{\mathrm{CHF}, \text { table }}^{\prime \prime}=f\left(G, P, X_{\mathrm{th}}\right), \\
q_{\mathrm{CHF}, \text { corrected }}^{\prime \prime}=\min \left(F_{\mathrm{CHF}, \text { gap }}, F_{\mathrm{CHF}, \text { size }}\right)\left(q_{\mathrm{CHF}, \text { table }}^{\prime \prime}\right), \\
F_{\mathrm{CHF, \text {gap }}}=\left[1-0.25\left(1-K_{X}\right)\right] \min \left(1,0.2+9 \frac{S}{d_{\text {rod }}}\right), \\
F_{\mathrm{CHF}, \text { size }}=\left(\frac{d_{\mathrm{hyd}}}{0.008}\right)^{-1 / 3} .
\end{gathered}
$$

3.4. Lateral Mixing. Lateral cross-flows are modelled empirically using the method described by Carlucci et al., which splits the mixing into a homogeneous component which is applied to both the liquid and vapour phases, and an incremental component which only affects the vapour [4]. The homogeneous component is based on the mixing rate per unit length relationship reported by Rogers and Tahir and is presented in (15) as a function of the homogeneous viscosity in (16) [4]. The incremental component for each phase was estimated using the least square that fits to experimental data as shown in (17) and (18), where $\Delta w_{l, 2 \phi}$ and $\Delta w_{g, 2 \phi}$ are fitting factors as a function of void fraction [4]. Adjustment factors $\left(F_{\text {mix,obs }}\right.$ and $\left.F_{\text {mix,gap }}\right)$ are used to account for mixing contributions stemming from obstructions in the flow or changes in the gap size, while $F_{\mathrm{mix}, G, p}$ fits the terms as a function of mass flux and pressure [4]. One has

$$
\begin{aligned}
& w_{\text {hom }}=\left[\mu_{\text {hom }} a_{w}\left(\frac{d_{\text {gap }}}{d}\right)^{b_{w}}\left(\frac{G d_{\text {hyd }}}{\mu_{\text {hom }}}\right)_{\text {hom }}^{0.9}\right], \\
& \mu_{\mathrm{hom}}=\left(\frac{x}{\mu_{g}}+\frac{1-x}{\mu_{l}}\right)^{-1} \text {, } \\
& w_{l}=w_{l, \mathrm{hom}}+w_{l, \text { inc }}, \\
& w_{l, \mathrm{hom}}=F_{\mathrm{mix}, \mathrm{obs}}(1-x) w_{\text {hom }}, \\
& w_{l, \text { inc }}=\frac{F_{\text {mix }, G, P} F_{\text {mix,gap }}}{F_{\text {mix }, \text { obs }}} \Delta w_{l, 2 \phi}, \\
& w_{g}=w_{g, \text { hom }}+w_{g, \text { inc }}, \\
& w_{g, \mathrm{hom}}=F_{\mathrm{mix}, \mathrm{obs}} x w_{\mathrm{hom}}, \\
& w_{g, \text { inc }}=\frac{F_{\text {mix }, G, p} F_{\text {mix,gap }}}{F_{\text {mix }, \text { obs }}} \Delta w_{g, 2 \phi} .
\end{aligned}
$$

3.5. Nodalization. Each subchannel was represented with 70 nodes in the axial direction. A pressure boundary condition was defined at the inlet while a mass flux boundary was

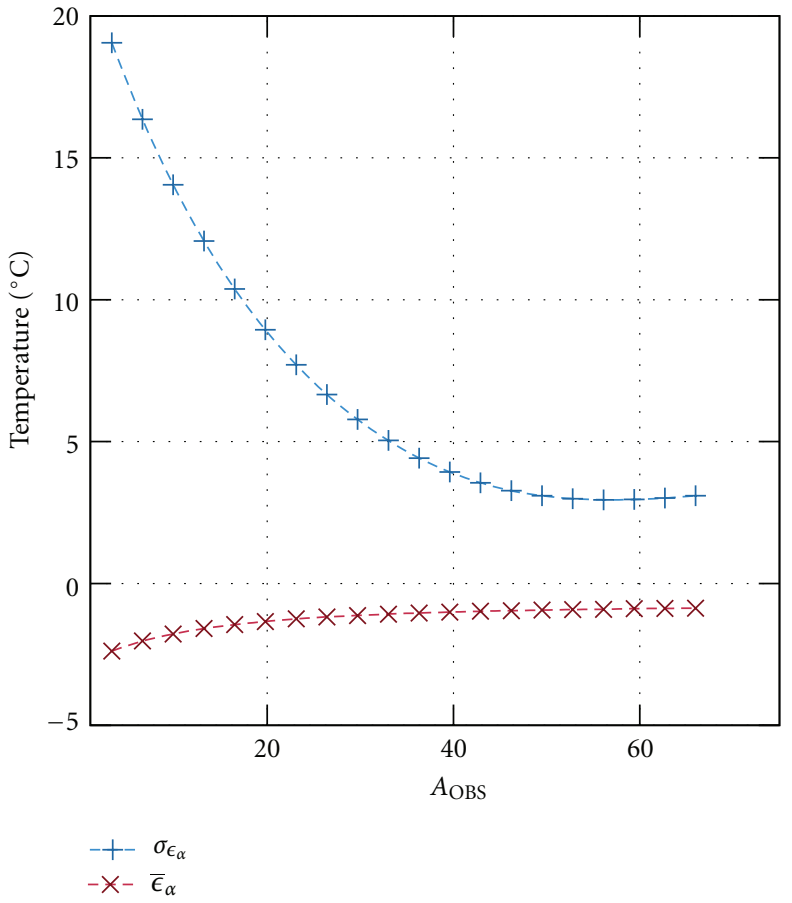

FIgure 3: Average and standard deviation of the error in fluid temperature as the magnitude of the obstruction mixing coefficient is increased.

imposed at the outlet. Channel walls surrounding the bundle were assumed to be adiabatic. Each of the heated rods was represented by collapsing the thermal conductivity, density, and specific heat capacity of the inconel and alumina into one effective value.

3.6. Mixing Vane Representation. In the Carlucci method, when the flow encounters an obstruction, it is assumed that the mixing rate is enhanced by a factor of $F_{\text {mix,obs. }}$. The magnitude of the enhancement factor is a product of a fitting coefficient, $A_{\mathrm{OBS}}$; and the loss or $k$-factor of the obstruction. As the flow moves downstream from the obstruction $\left(z_{\mathrm{obs}}\right)$, the magnitude of the multiplier is reduced as a function of the decay coefficient $B_{\mathrm{OBS}}$.

$$
F_{\text {mix }, \text { obs }}=\left(1+A_{\mathrm{OBS}}(k)\left(\exp \left[-B_{\mathrm{OBS}} \frac{z_{\mathrm{obs}}}{d_{\mathrm{hyd}}}\right]\right)\right) .
$$

The ASSERT code is primarily used to model PHWR fuel channels which, unlike LWRs, do not contain mixing vanes. Since the mixing in the current benchmark is anticipated to be much stronger than in PHWR bundles, the default values for $A_{\mathrm{OBS}}$ and $B_{\mathrm{OBS}}$ are expected to underrepresent the effects of the vane type obstructions. However the exact geometry of the mixing grids were not released, and so a study on the magnitude of the mixing effects was conducted in order to establish the appropriate values for the lateral momentum source term.

In order to develop a reasonable representation of the lateral flows in the bundle occurring due to obstructions, the mixing vanes and spacer grids were modelled in a manner 


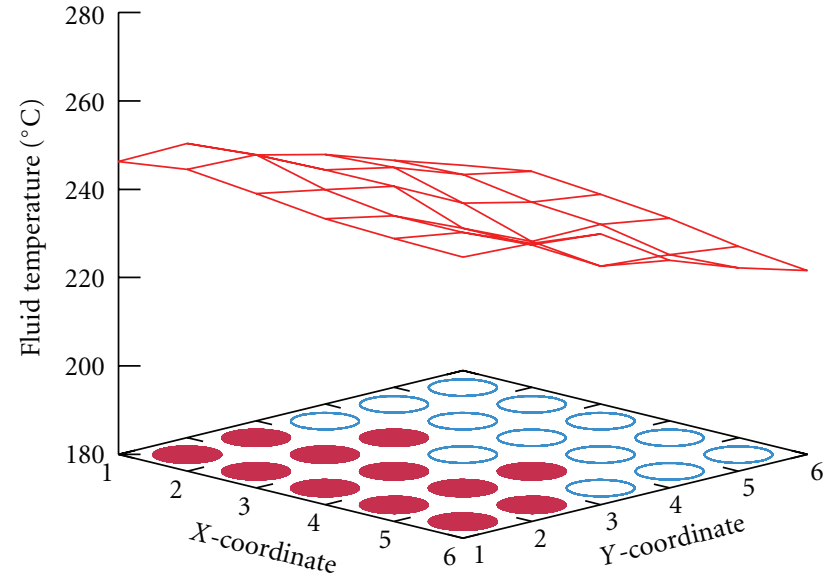

Figure 4: Measured outlet fluid temperature for Case 01-3233. Shaded rods operate at 4 times the power of the unshaded rods.

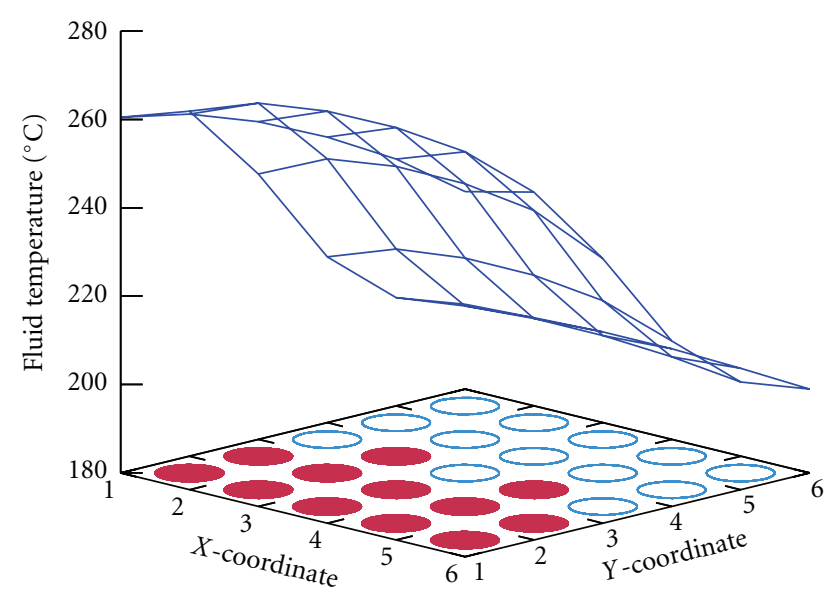

(a)

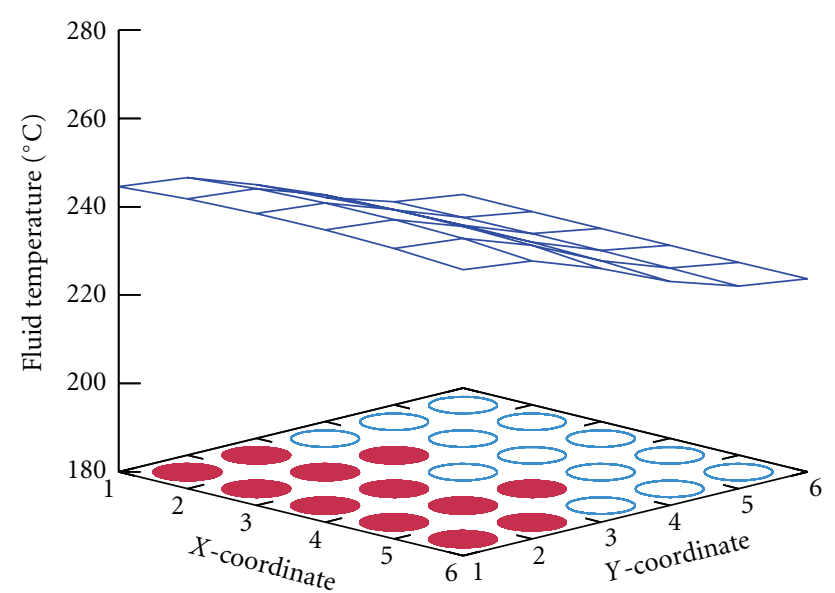

(b)

Figure 5: Predicted outlet fluid temperature for Case 01-3233 with $A_{\mathrm{OBS}}=3.3$ (a) and $A_{\mathrm{OBS}}=49.5$ (b). Shaded rods operate at 4 times the power of the unshaded rods.

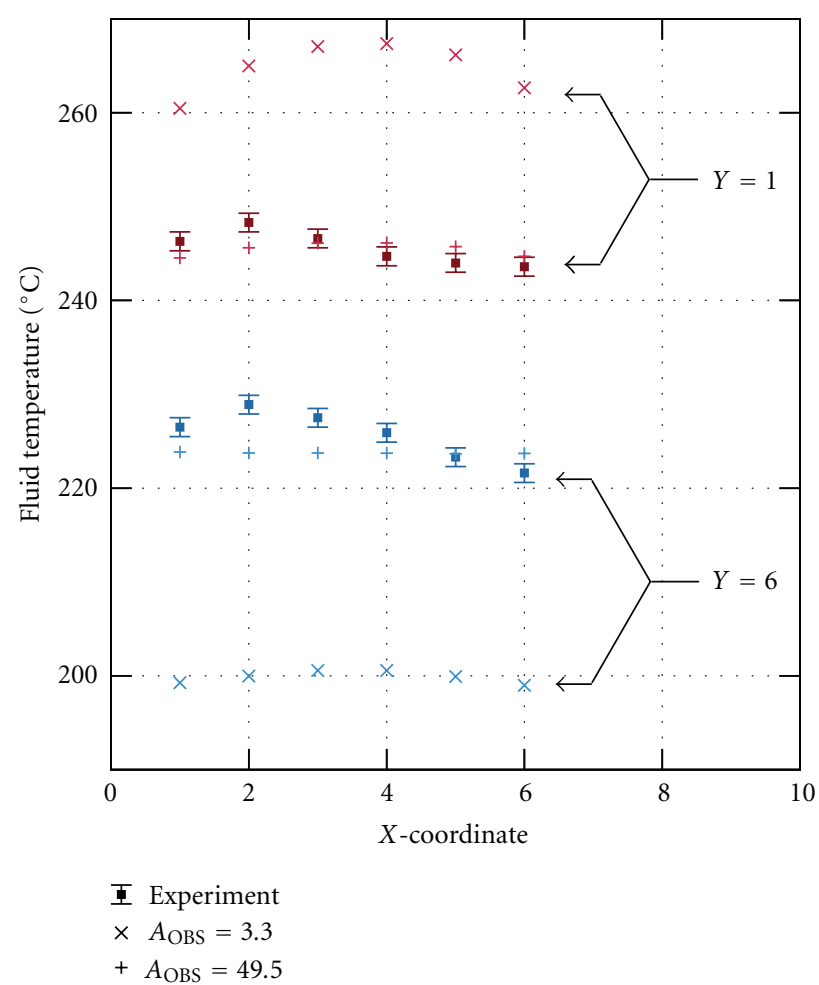

FIGURE 6: Outlet fluid temperatures along the hot side $(Y=1)$ and cold side $(Y=6)$ of the bundle for case 01-3233.

similar to that described by [5]. The method assumes that the $k$-factor for each obstruction consists of a geometric and a frictional component, with both being functions of the blockage area $\chi$. Each feature of the grid or vane is projected onto a plane perpendicular to the axial flow. Based on these projections, an effective blockage area and effective wetted perimeter were derived for each subchannel in the bundle. Idelchik's formula for losses from a sharp-edged orifice was then used to derive $k$-factors [6]. The derived values for each subchannel for the mixing vanes and spacer grids are provided in Tables 3 and 4 and are based on the approximate dimensions supplied by [1]. The reported values indicate that while the simple spacer may be regarded as a symmetric object, the mixing vane contains a degree of asymmetry to it.

$$
\begin{gathered}
k=k_{\text {geom }}+k_{\text {friction }}, \\
\chi=\frac{A_{\text {block }}}{A_{\text {up }}}, \\
k_{\text {geom }}=\left(\frac{\sqrt{0.5 \chi+\chi}}{1-\chi}\right)^{2}, \\
k_{\text {friction }}=\frac{f L P_{\text {up }}}{4 A_{\text {up }}}\left[\frac{P_{\text {block }}}{P_{\text {up }}}\left(\frac{1}{\chi}\right)^{3}-1\right] .
\end{gathered}
$$

The value for the decay coefficient $B_{\mathrm{OBS}}$ is by default set to $B_{\mathrm{OBS}}=0.013$ which causes the mixing enhancement due to obstructions to be reduced to $50 \%$ of the peak value 


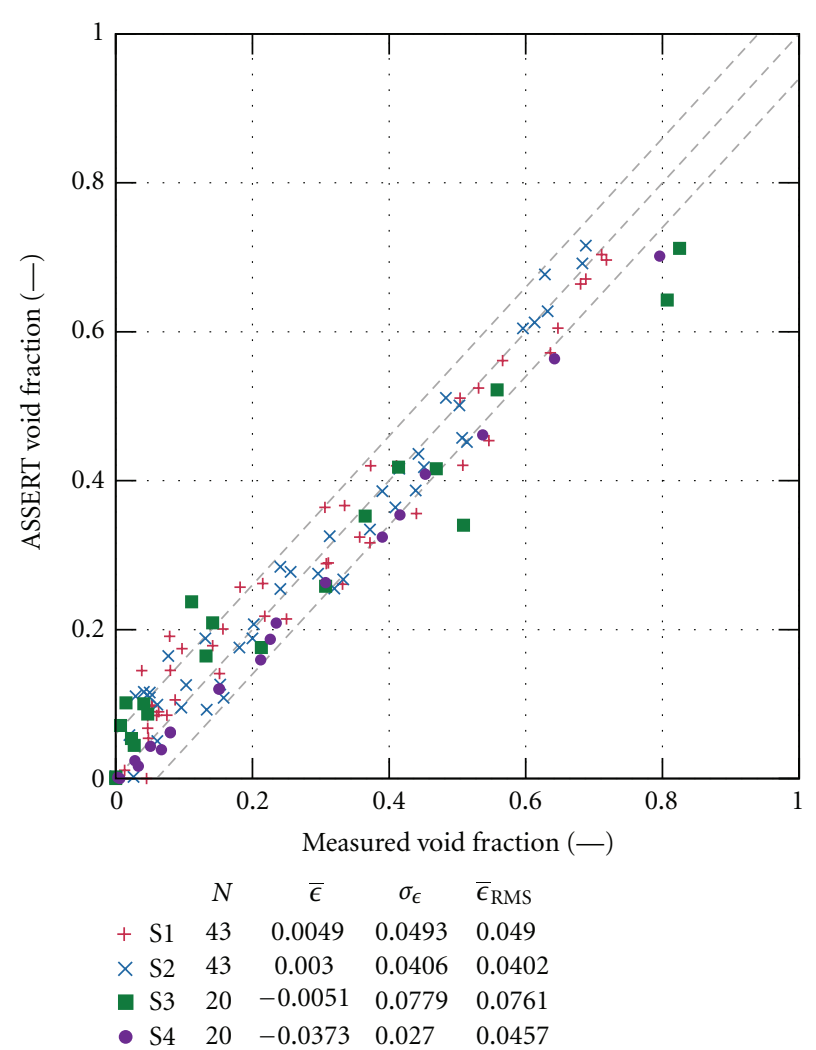

(a)

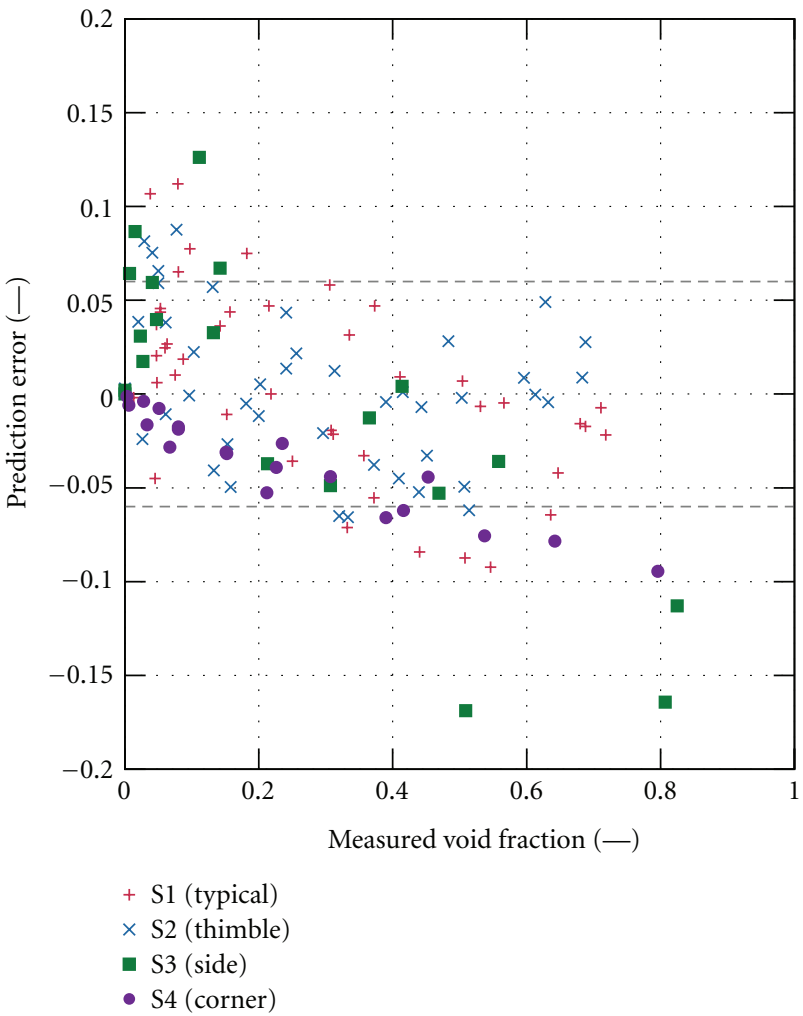

(b)

FIgURE 7: Code accuracy in predicting void fraction in a single isolated subchannel. Predicted versus measured results (a) and error versus measured void fraction (b). Error bands displayed correspond to $2 \sigma=0.06$.

TABLE 3: $k$-factors for the simple spacer.

\begin{tabular}{llllll}
\hline 0.410 & 0.326 & 0.326 & 0.326 & 0.326 & 0.410 \\
0.326 & 0.236 & 0.236 & 0.236 & 0.236 & 0.326 \\
0.326 & 0.236 & 0.236 & 0.236 & 0.236 & 0.326 \\
0.326 & 0.236 & 0.236 & 0.236 & 0.236 & 0.326 \\
0.326 & 0.236 & 0.236 & 0.236 & 0.236 & 0.326 \\
0.410 & 0.326 & 0.326 & 0.326 & 0.326 & 0.410 \\
\hline
\end{tabular}

TABLE $4: k$-factors for the mixing vane.

\begin{tabular}{llllll}
\hline 0.534 & 0.915 & 0.915 & 0.915 & 0.915 & 1.200 \\
0.915 & 0.942 & 0.942 & 0.942 & 0.942 & 0.921 \\
0.915 & 0.942 & 0.942 & 0.942 & 0.942 & 0.921 \\
0.915 & 0.942 & 0.942 & 0.942 & 0.942 & 0.921 \\
0.915 & 0.942 & 0.942 & 0.942 & 0.942 & 0.921 \\
1.200 & 0.915 & 0.915 & 0.915 & 0.915 & 0.568 \\
\hline
\end{tabular}

after approximately 9 hydraulic diameters downstream from the blockage. This value is derived for PHWR type fuel channels since the appendages encountered by the flows are typically less disruptive than what would be characteristic of a mixing vane. While the exact geometry of the vanes was not released for proprietary reasons, literature demonstrates that in experiments with similar split vane type spacers, the mixing enhancement is reduced to $50 \%$ of the initial value after travelling about $20 d_{\text {hyd }}$ downstream from the obstruction [7]. The decay coefficient is therefore set to $B_{\mathrm{OBS}}=0.033$ in order to reflect this PWR type obstruction behaviour.

The derivation of an appropriate value for $A_{\mathrm{OBS}}$ comes from the examination of a single case from the fluid temperature distribution tests of series A1. The experimental conditions of this test are summarized in Table 5, and are set so that the fluid is in single phase at the outlet. As illustrated in Figure 1, 12 of the 25 rods are heated with 4 times more power than the others. Using the default value for the mixing magnitude coefficient, $A_{\mathrm{OBS}}=3.3$, the initial results illustrated in Figures 5 and 6 indicate that the subchannels on the "hot" side of the bundle are at significantly a higher temperature while those on the "cold" side are substantially cooler than what was observed in the experiment. Quantitatively, this is represented by a bundle averaged temperature error of $\bar{\epsilon}=-2.38^{\circ} \mathrm{C}$ with a standard deviation of $\sigma_{\epsilon}=19.06^{\circ} \mathrm{C}$ and is consistent with what would be expected if the lateral momentum source term was underpredicting what was occurring in the experiment.

Increasing the value of $A_{\mathrm{OBS}}$ enhances the magnitude of the mixing, and as illustrated in Figure 3, significantly reduces the standard deviation of the error. For the mixing 


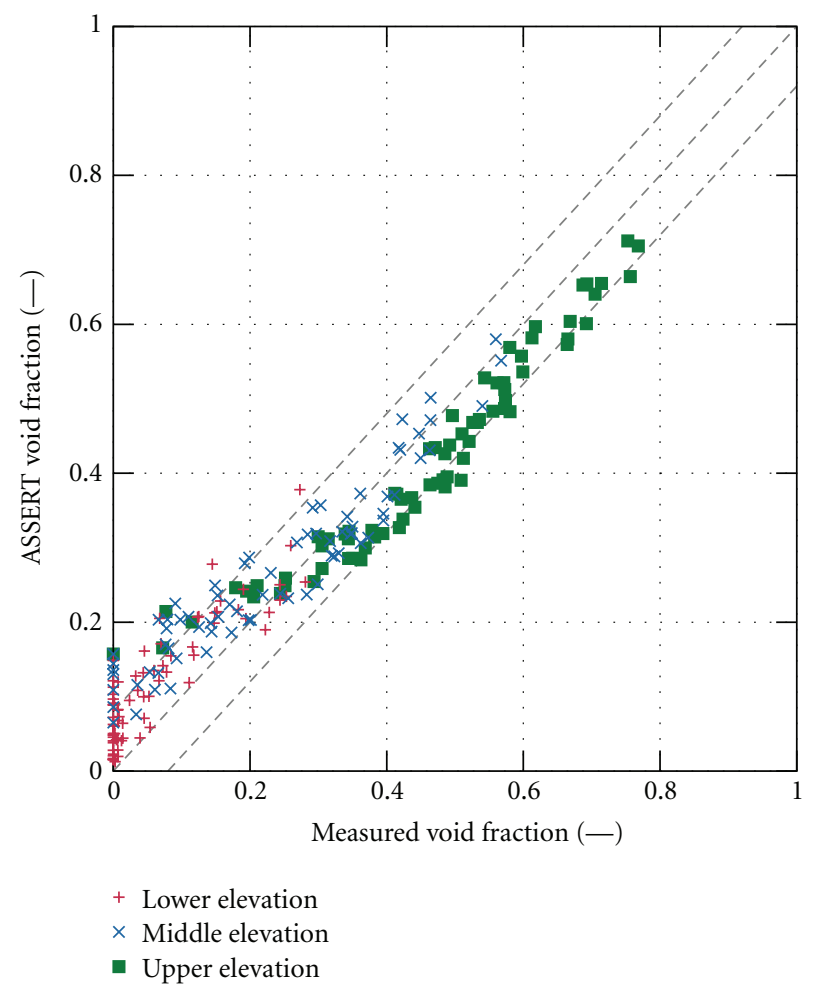

(a)

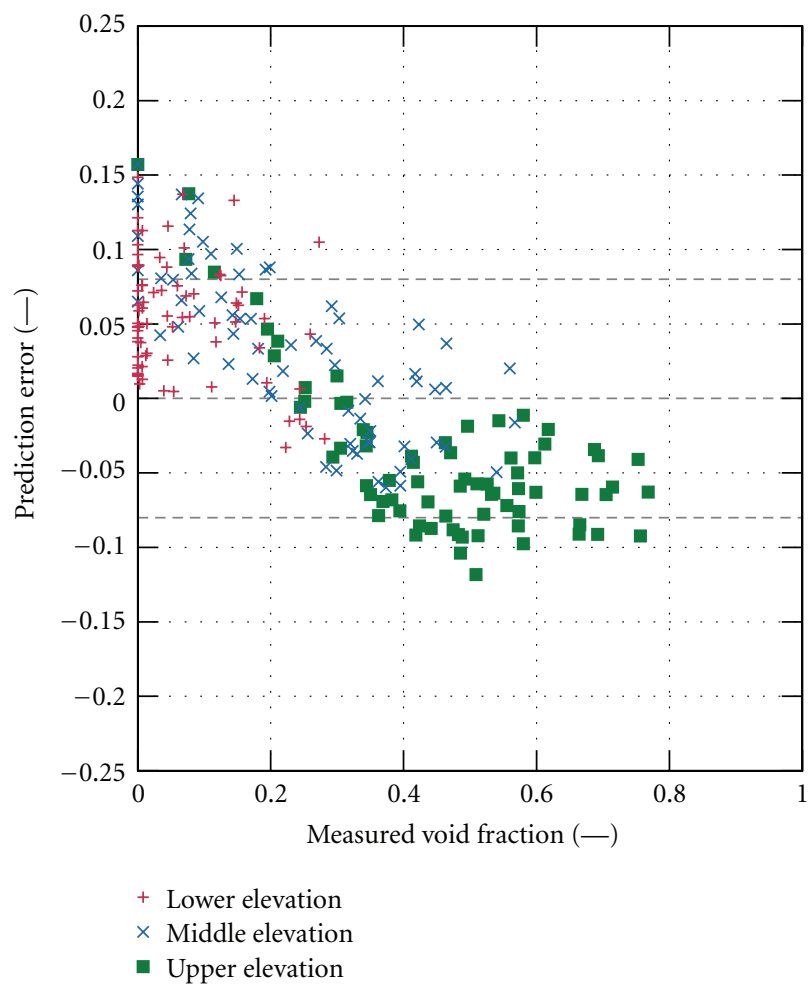

(b)

FIGURE 8: Steady state void fraction results for bundle test series B5. Error bands displayed correspond to $2 \sigma_{\text {exp }}=0.08$.

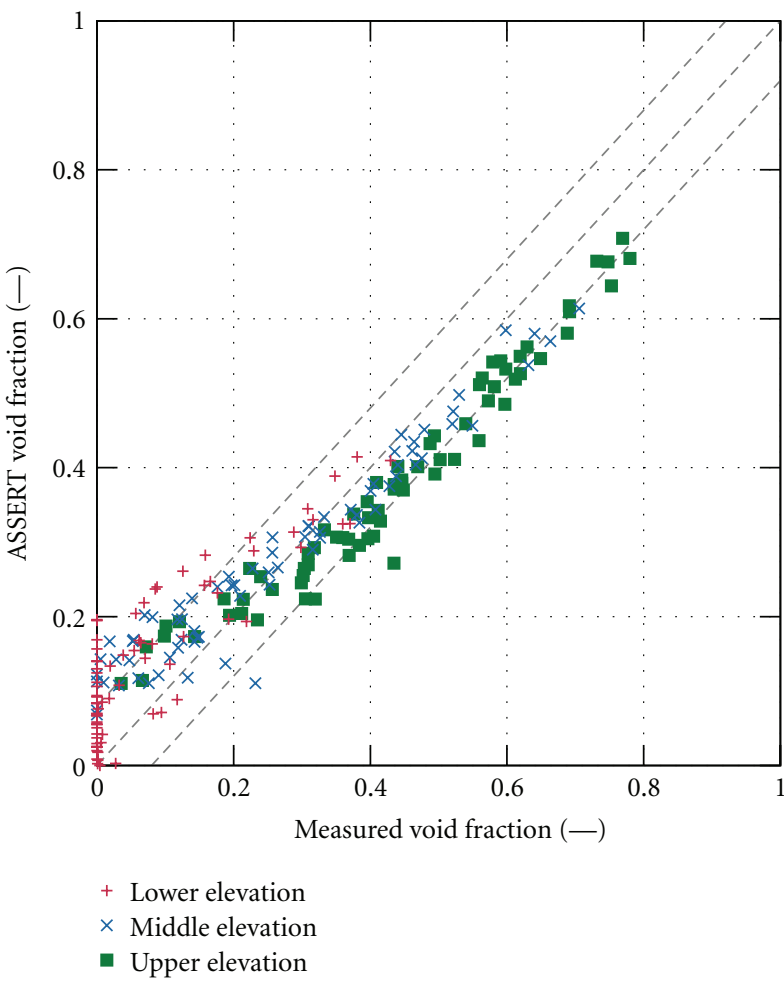

(a)

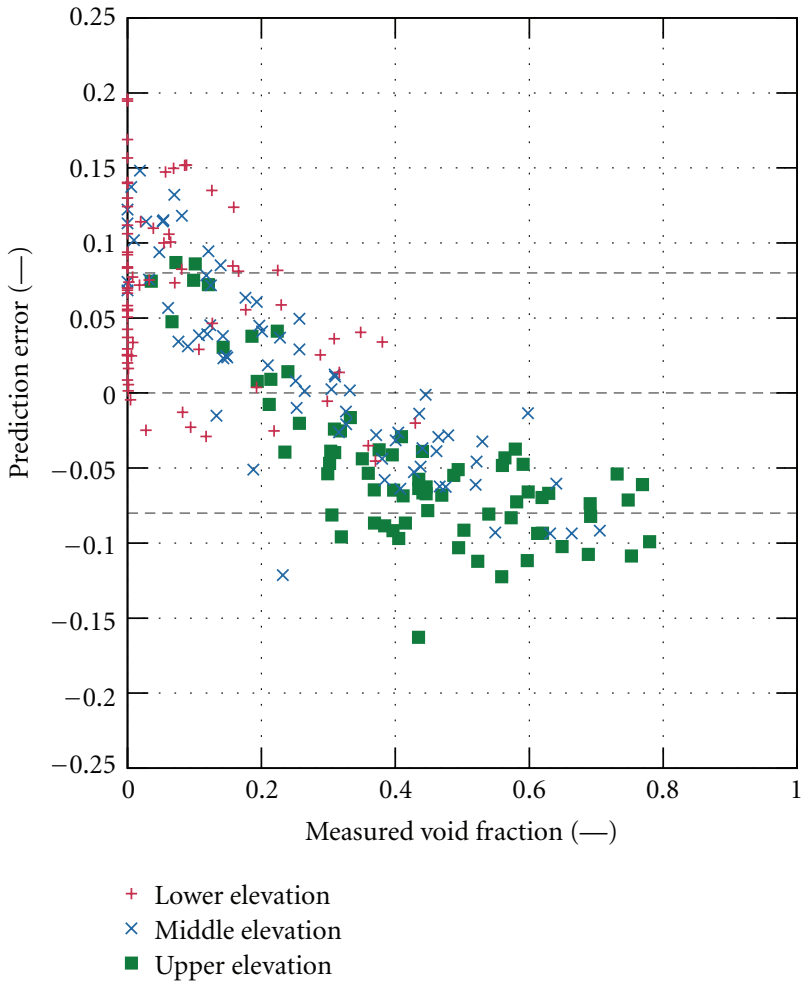

(b)

FIGURE 9: Steady state void fraction results for bundle test series B6. Error bands displayed correspond to $2 \sigma_{\text {exp }}=0.08$. 


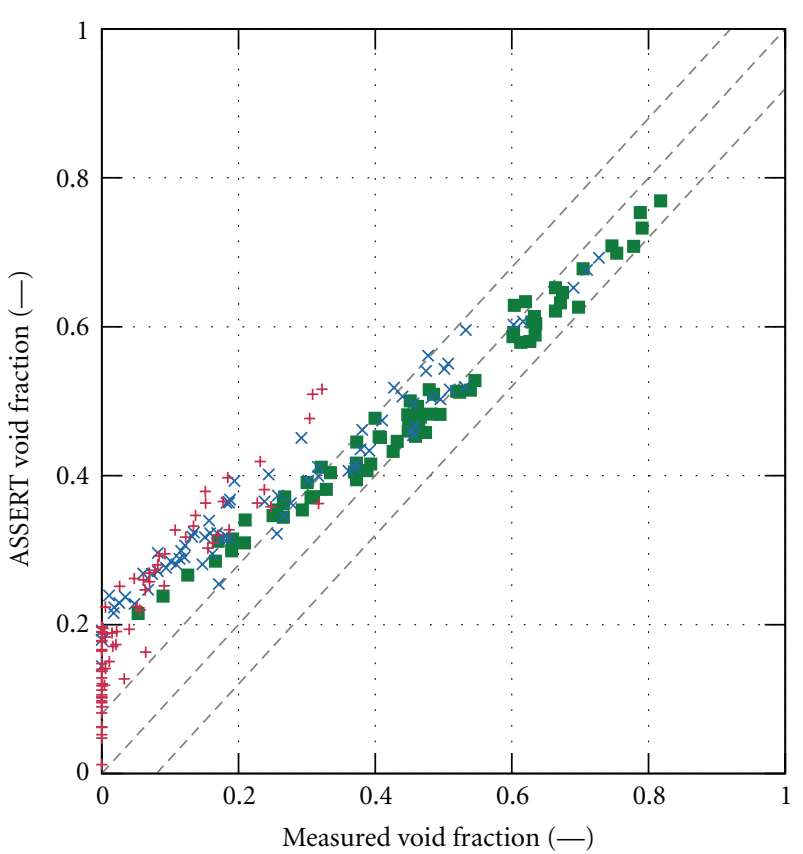

+ Lower elevation

$\times$ Middle elevation

- Upper elevation

(a)

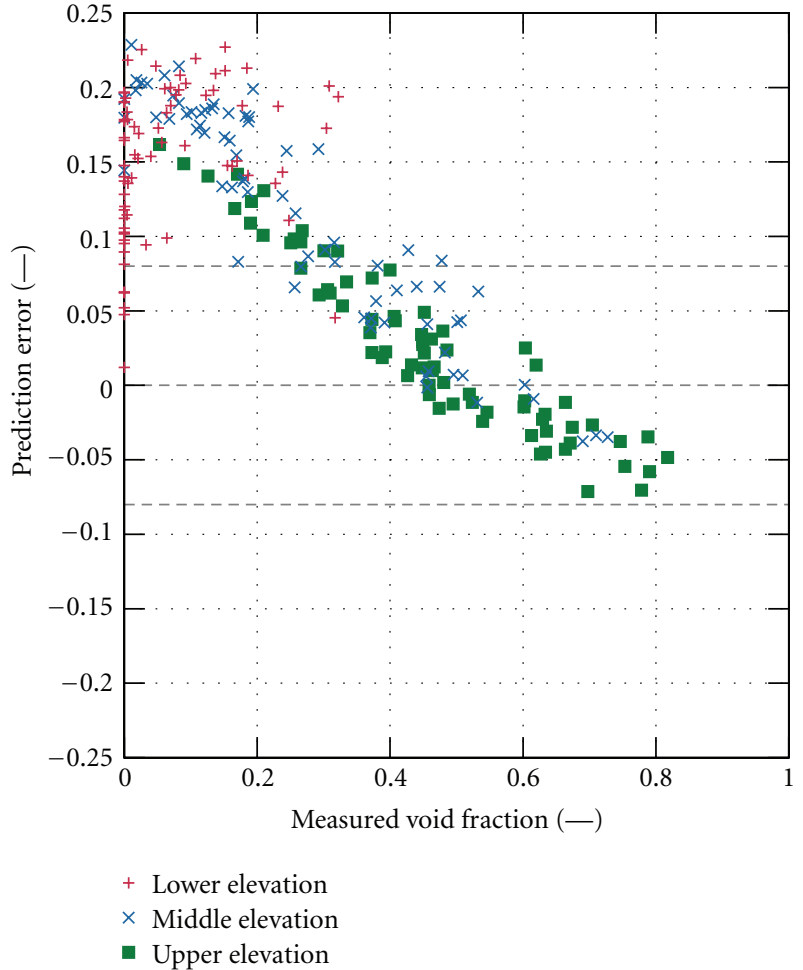

(b)

FIGURE 10: Steady state void fraction results for bundle test series B7. Error bands displayed correspond to $2 \sigma_{\exp }=0.08$.

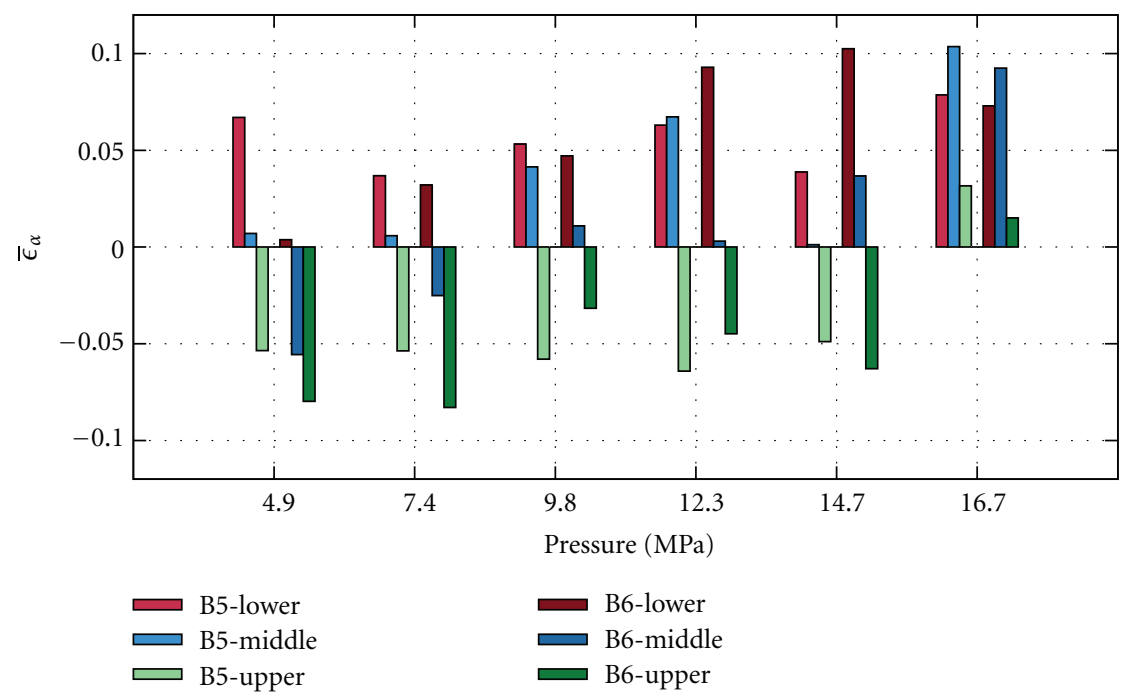

FIGURE 11: Steady state void fraction error for bundles B5 and B6 arranged by system pressure.

vanes used in the current benchmark, $\sigma_{\epsilon}$ has a minimum value at $A_{\mathrm{OBS}}=49.5$. Figure 5 illustrates the outlet fluid temperature predicted by ASSERT using the increased mixing and shows good qualitative agreement with the experimental results in Figure 4. The minor improvement in the bundle averaged error is an artifact stemming from fact that the bundle average was taken by summing the temperature of each of the subchannels and dividing by the number of subchannels, rather than weighting each by the mass flow rate. At $A_{\mathrm{OBS}}=49.5$, the bundle averaged error was 


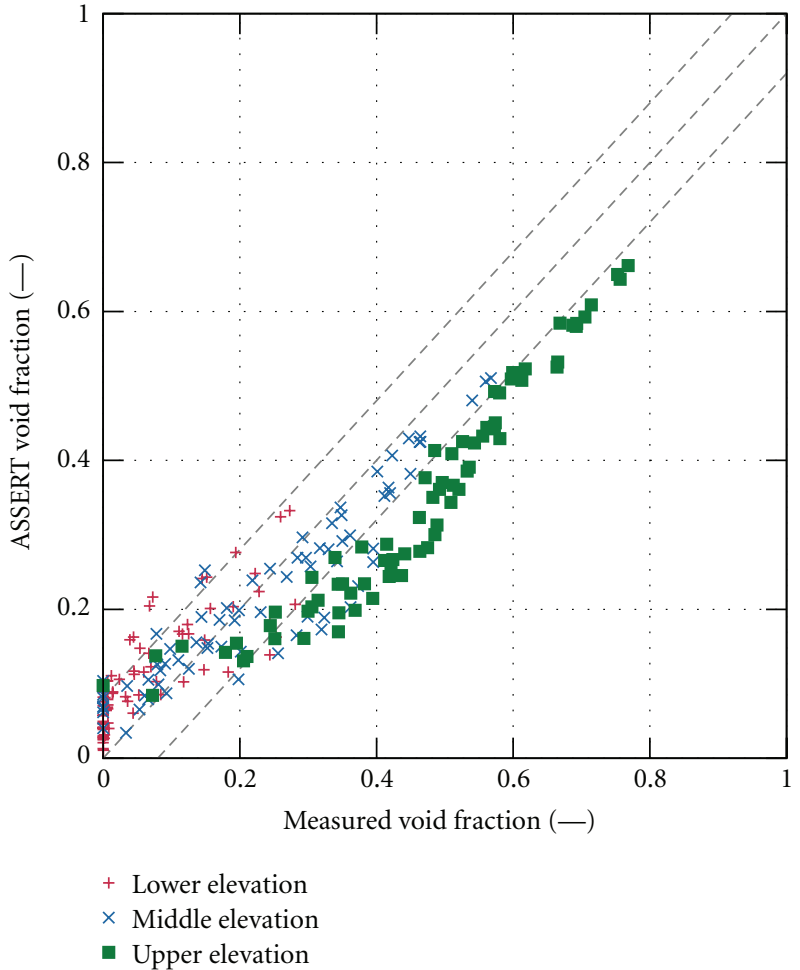

(a)

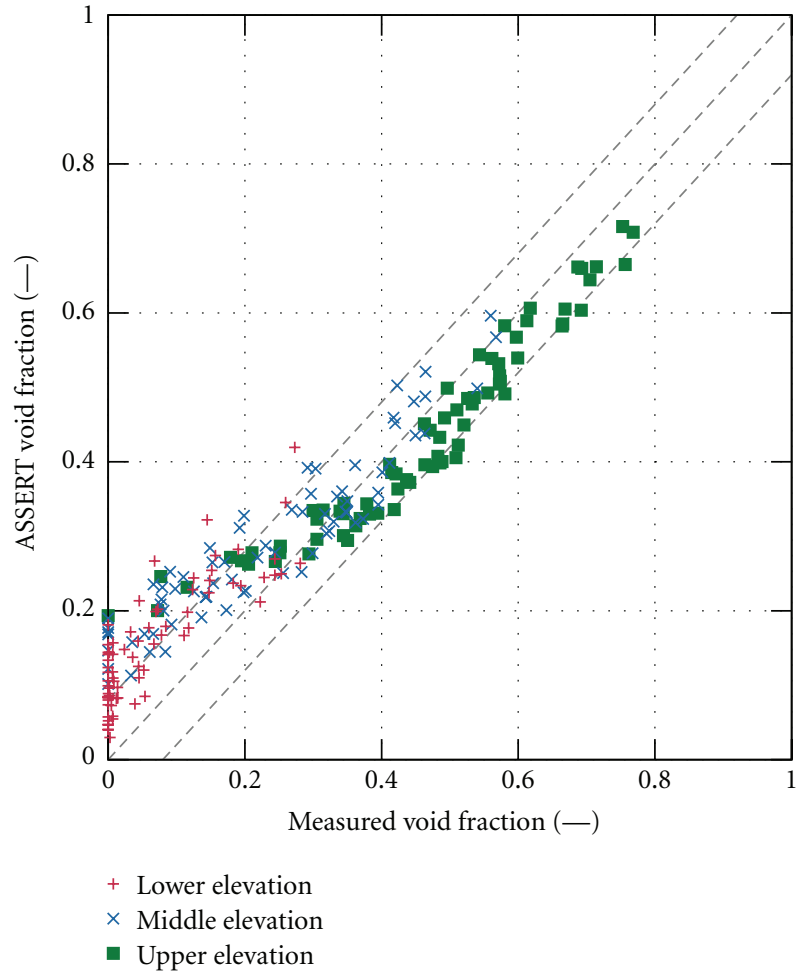

(b)

FIGURE 12: Steady state void fraction results for bundle B5 using the Chen (a) and Lahey (b) two-phase heat transfer correlations. Error bands displayed correspond to $2 \sigma_{\exp }=0.08$.

TABLE 5: Test conditions for case 01-3233.

\begin{tabular}{lc}
\hline Parameter & Value \\
\hline Pressure $(\mathrm{MPa})$ & 9.81 \\
Mass flux $\left(\mathrm{Mg} / \mathrm{m}^{2} \mathrm{~s}\right)$ & 1.28 \\
Temperature $\left({ }^{\circ} \mathrm{C}\right)$ & 166.1 \\
Bundle power $(\mathrm{MW})$ & 0.98 \\
\hline
\end{tabular}

$\bar{\epsilon}=-0.91^{\circ} \mathrm{C}$ and is within the bounds of the uncertainty of the temperature measurements, which was estimated to be $\pm 1^{\circ} \mathrm{C}$.

\section{Results}

In this section, a comparison of the ASSERT predictions to the PSBT experimental data is conducted for both the void fraction and the DNB tests. Additionally, sensitivity studies were performed in order to determine the effects of correlation selection.

4.1. Void Fraction. The steady state void fraction portion of the benchmark is divided into two portions: an "isolated subchannel" portion, and a "bundle" portion. In addition, a transient bundle set of data was also run by the participants. The experimental uncertainty in the void fraction has been discussed in depth during the benchmark meetings and is well summarized by [8].
4.1.1. Steady State Single Subchannel. A total of 126 cases using the single subchannel were assessed against experimental data. Table 6 indicates that about $77.0 \%$ of all simulated void fractions fell within $\pm 2 \sigma_{\operatorname{Exp}}$ of the measured value. However the code exhibits a slight tendency to overpredict at low void fractions, while underpredicting at higher values as illustrated in Figure 7. This trend is particularly evident in the S3 and S4 series of tests which represented the side and corner subchannel geometries. Using $\epsilon_{\alpha}=\alpha_{\text {ASSERT }}-\alpha_{\exp }$ as the definition for the code error, the average error $\left(\bar{\epsilon}_{\alpha}\right)$ for the S3 series of tests was found to be -0.0051 while the root mean square error $\left(\bar{\epsilon}_{\mathrm{RMS}}\right)$ was 0.0761 -which is almost twice that of the other geometries. Several outliers contribute significantly to this at higher void fractions, where in some cases ASSERT underpredicts the measured value by more than 0.15. The ASSERT underprediction for these specific test cases is however consistent with the results reported by other codes and may be an artifact of the measurement process $[8,9]$.

4.1.2. Steady State Bundle. The steady state bundle results are found in Figures 8, 9, and 10 with a statistical breakdown of the predictions in Table 7 . The reported values for both the experimental and simulated void fractions represent the average over the 4 subchannels surrounding the center rod of the bundle. The results for bundles B5 and B6 are similar with the average void error differing by approximately 0.01 at each of the measurement elevations. This is not a surprising 


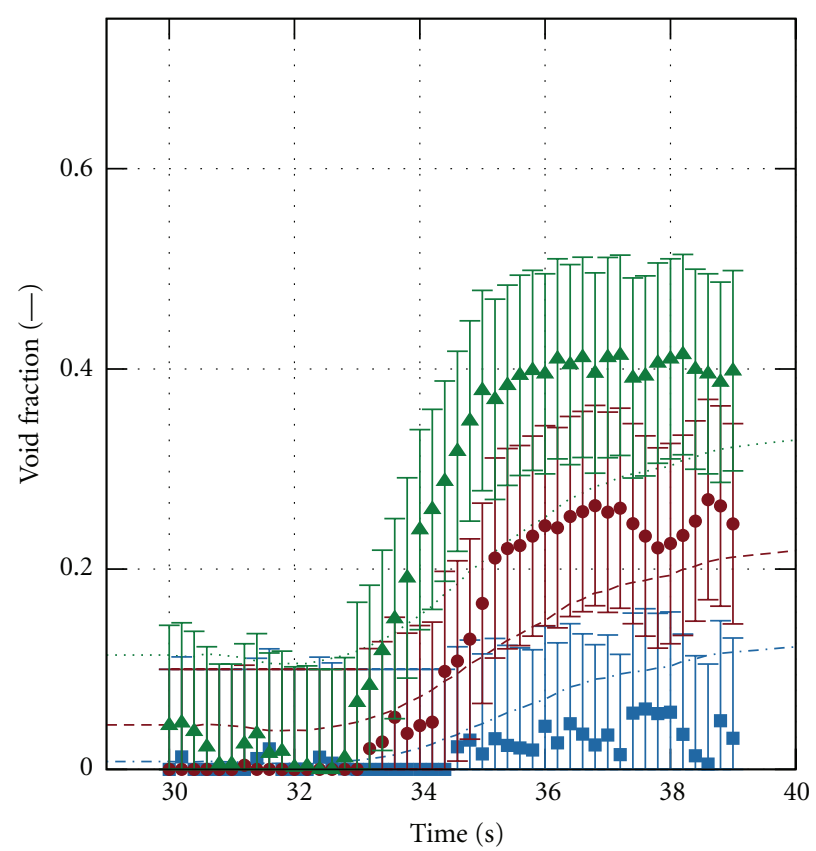

(a)

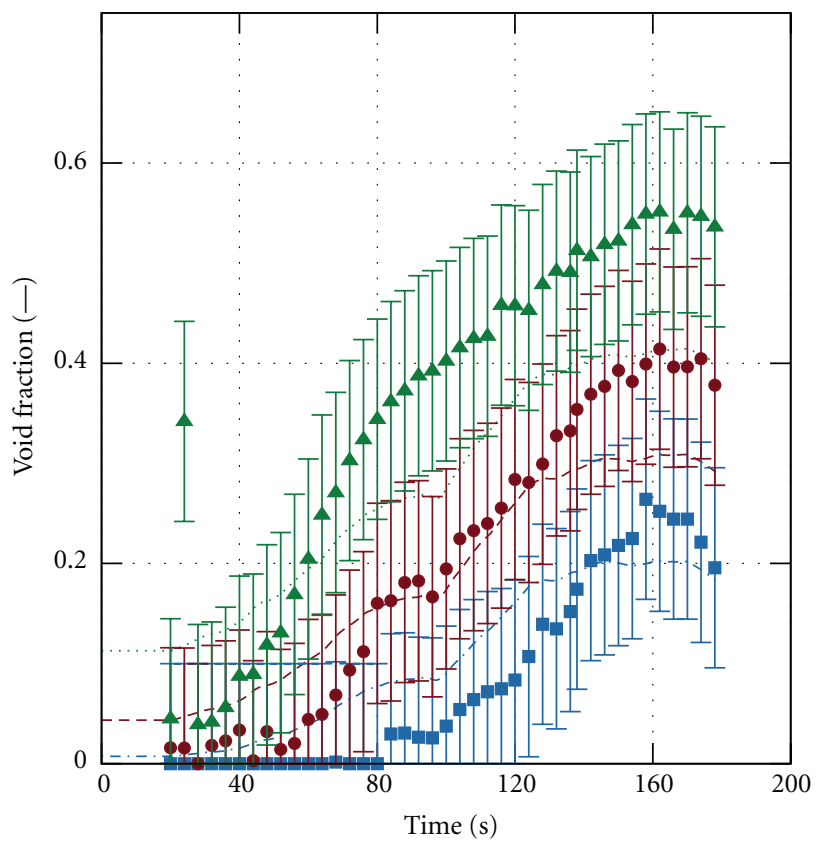

ASSERT experiment

….. $\Delta$ Upper

- - • Middle

... Lower

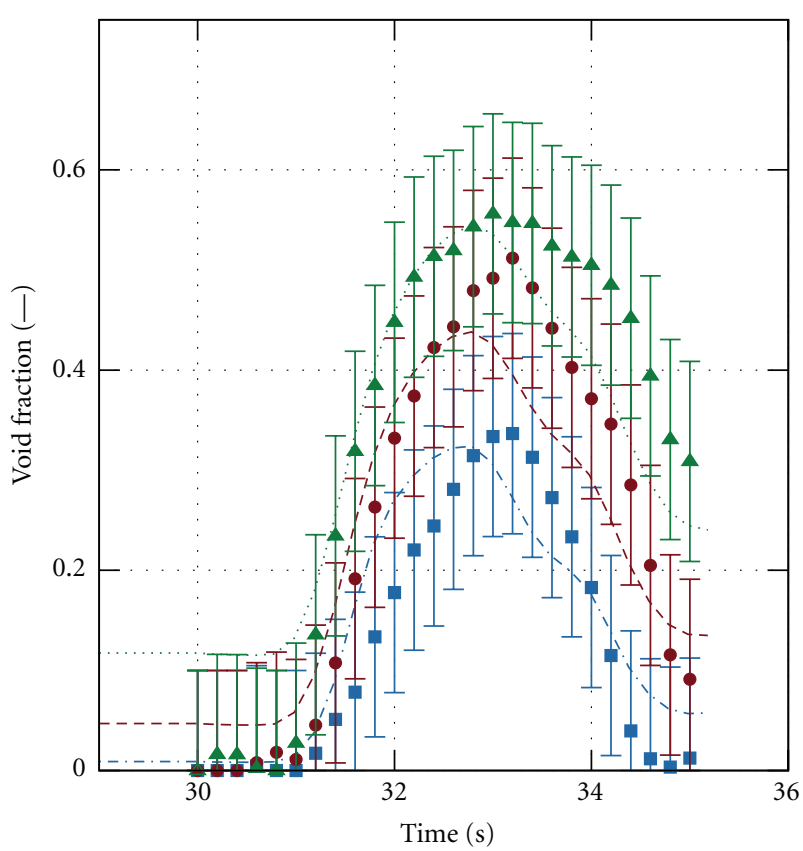

(b)

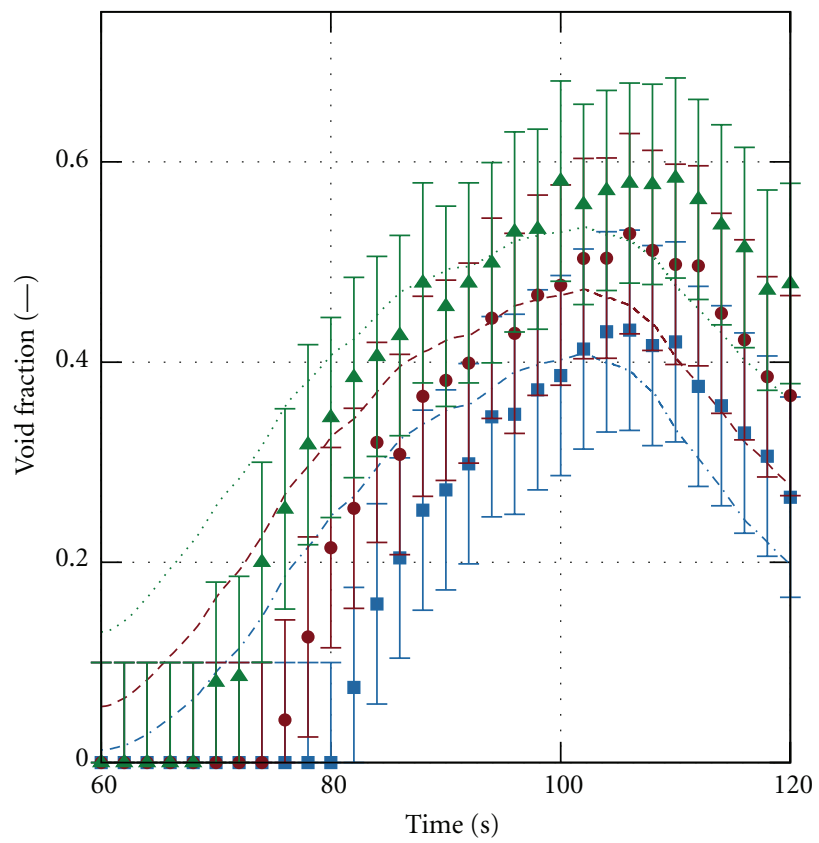

ASSERT experiment

…. $\Delta$ Upper

--- Middle

...- Lower

(c)

(d)

FIgURE 13: Transient void fraction results for bundle test series B5. Power increase (a), flow reduction (b), depressurization (c), and inlet temperature increase (d). Error bands displayed correspond to $2 \sigma_{\exp }=0.10$.

result as the bundles have identical geometries, and only the radial power distribution differs between them. The void predictions for bundle B7 are worse however at low void fractions, with an average overestimation of 0.15 at the bottom measurement elevation. From this, it is possible to infer that changing the axial power profile-as in the case of B5 and B6-has a minor effect on the accuracy of the void predictions. However, the addition of the unheated thimble 


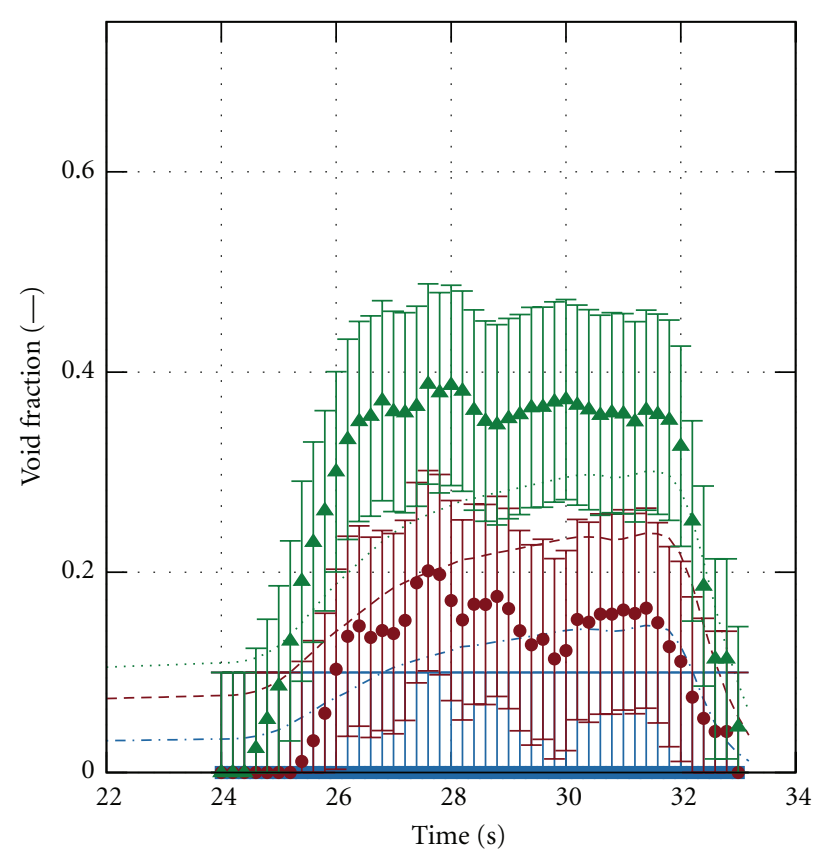

(a)

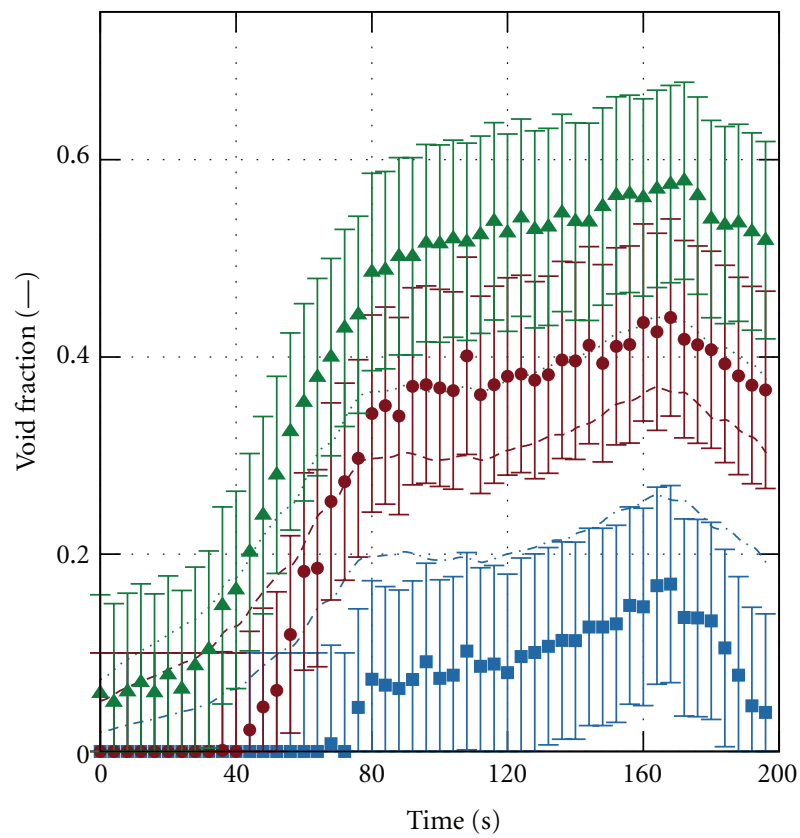

ASSERT experiment

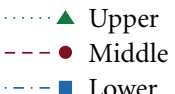

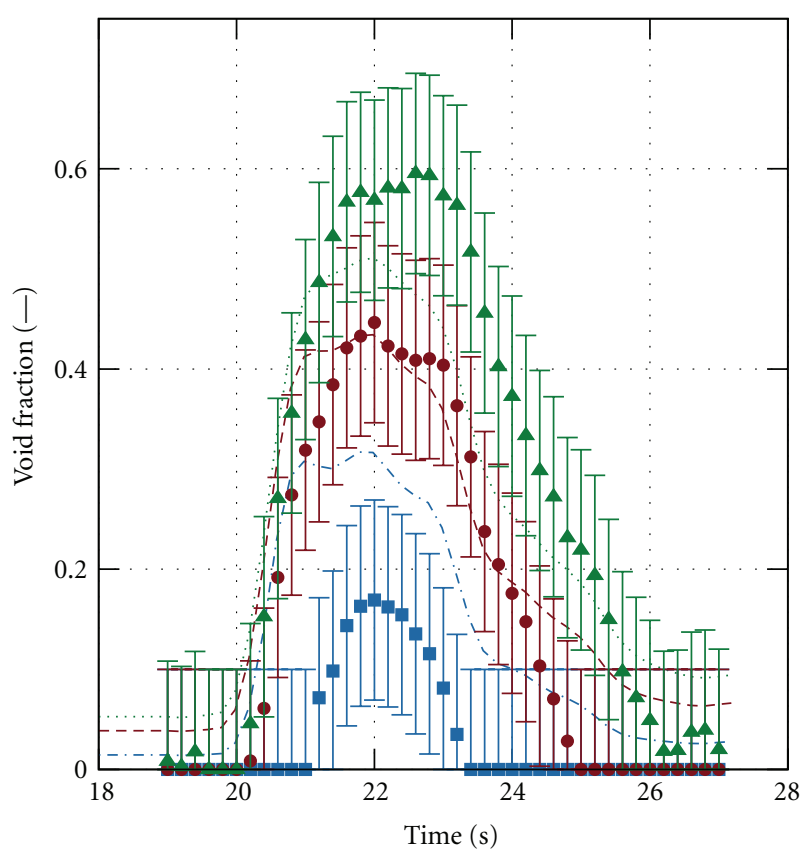

(b)

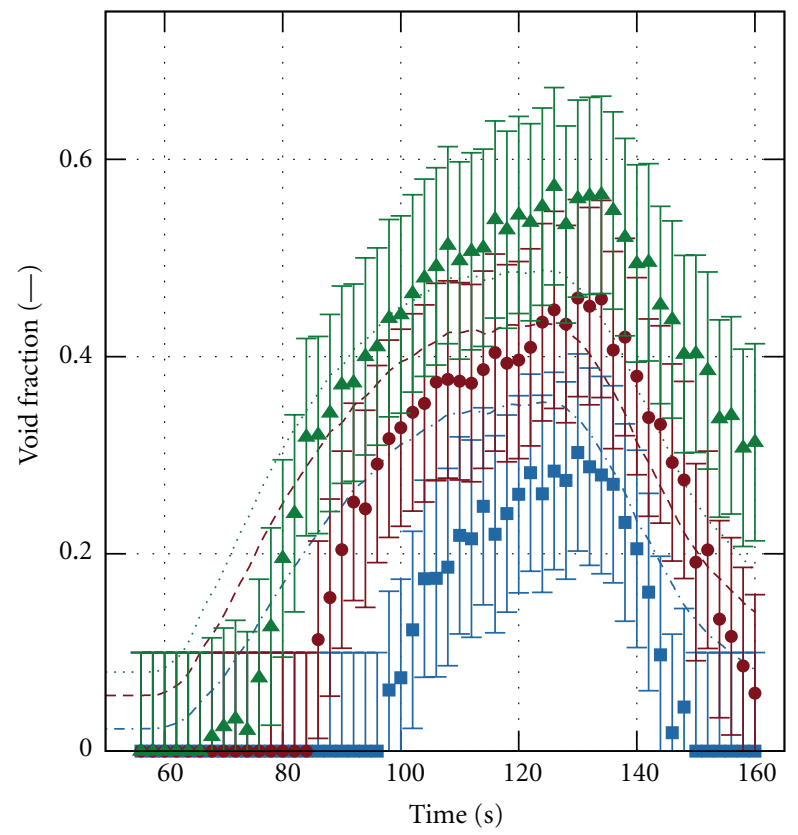

ASSERT experiment

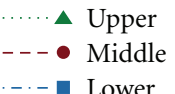

(c)

(d)

Figure 14: Transient void fraction results for bundle test series B6. Power increase (a), flow reduction (b), depressurization, (c) and inlet temperature increase (d). Error bands displayed correspond to $2 \sigma_{\exp }=0.10$.

rod in the middle of the bundle plays a more significant role in affecting the overall accuracy of the void predictions, and this is perhaps due to condensation effects which are not explicitly modelled in ASSERT.
The void fraction overprediction in the subcooled region is not entirely unexpected since the two-phase heat transfer correlation was derived from data fitted at lower pressures relative to the current study. In the original work by Ahmad, 


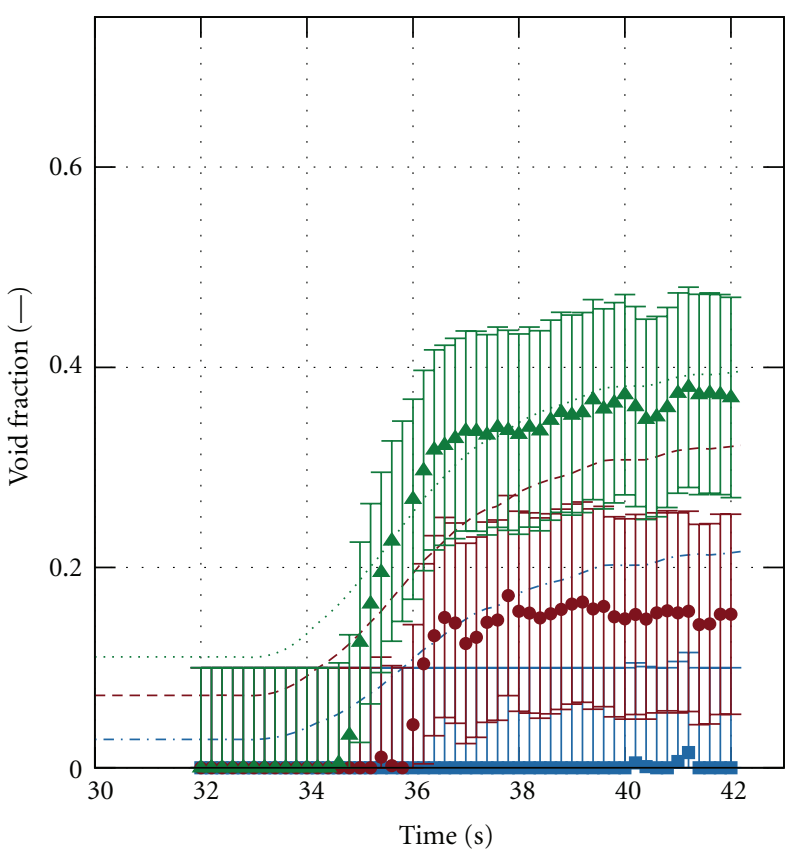

(a)

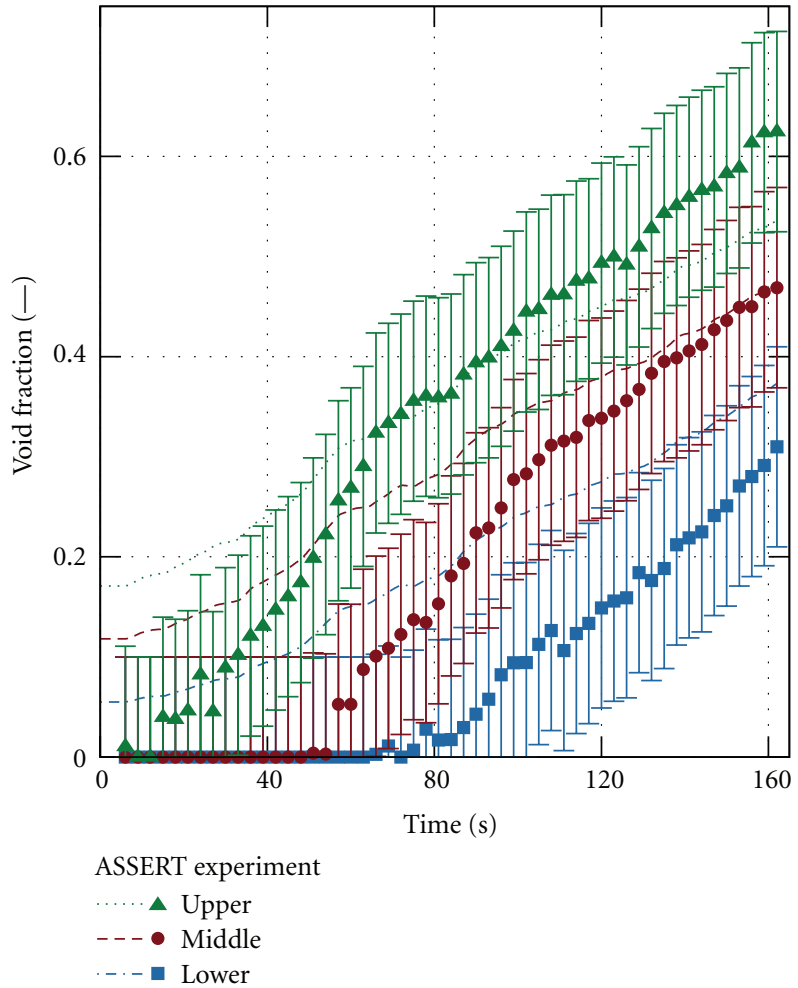

(c)

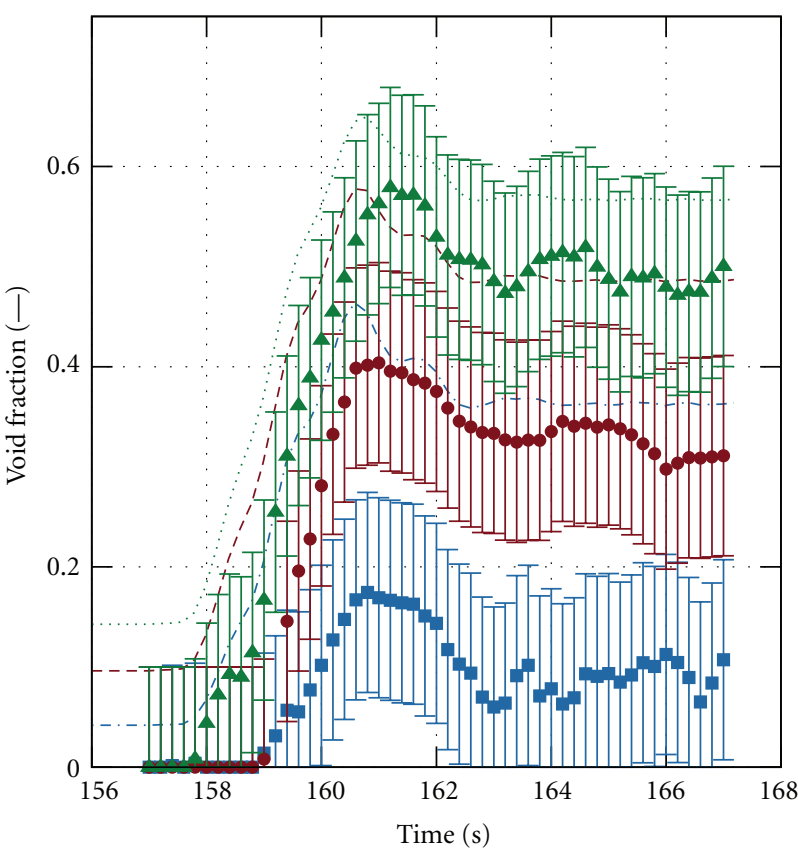

(b)

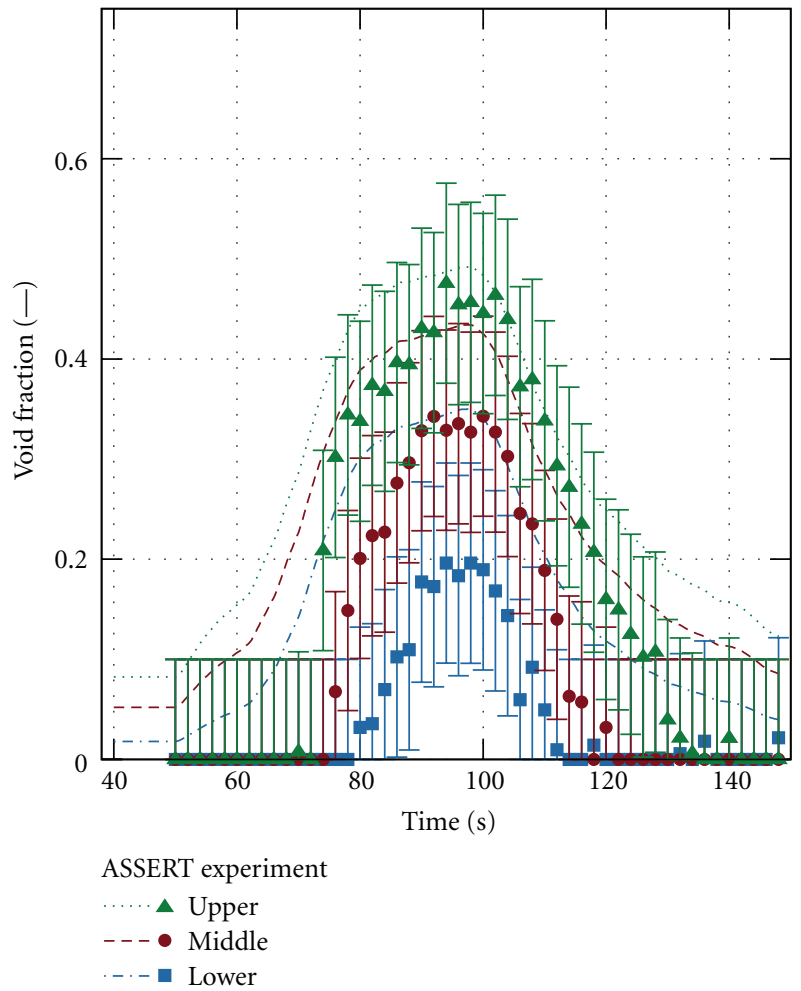

(d)

Figure 15: Transient void fraction results for bundle test series B7. Power increase (a), flow reduction (b), depressurization (c), and inlet temperature increase (d). Error bands displayed correspond to $2 \sigma_{\exp }=0.10$.

the correlations yielded accurate predictions of the void fraction in a tube under conditions where the pressure was less than 11.03 MPa [2]. However, the paper also compares the derived correlation against the experimental data of
Egen et al. which was taken at $13.79 \mathrm{MPa}$, and found in several cases that the void fraction would be overpredicted by up to 0.10 near the transition between the subcooled and saturated boiling regimes, which is consistent with the 


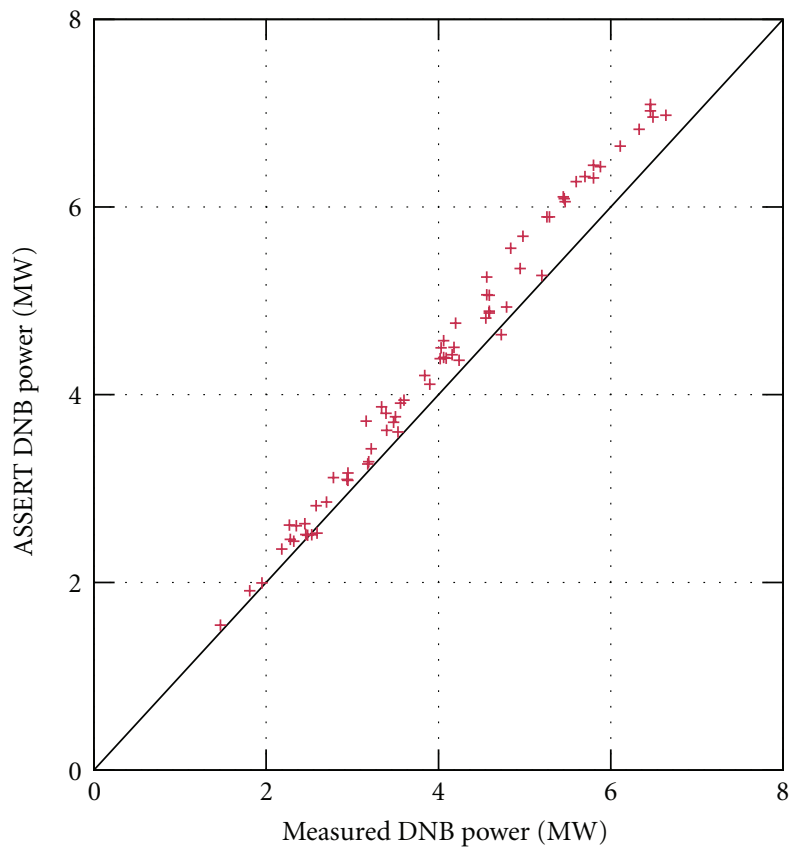

(a)

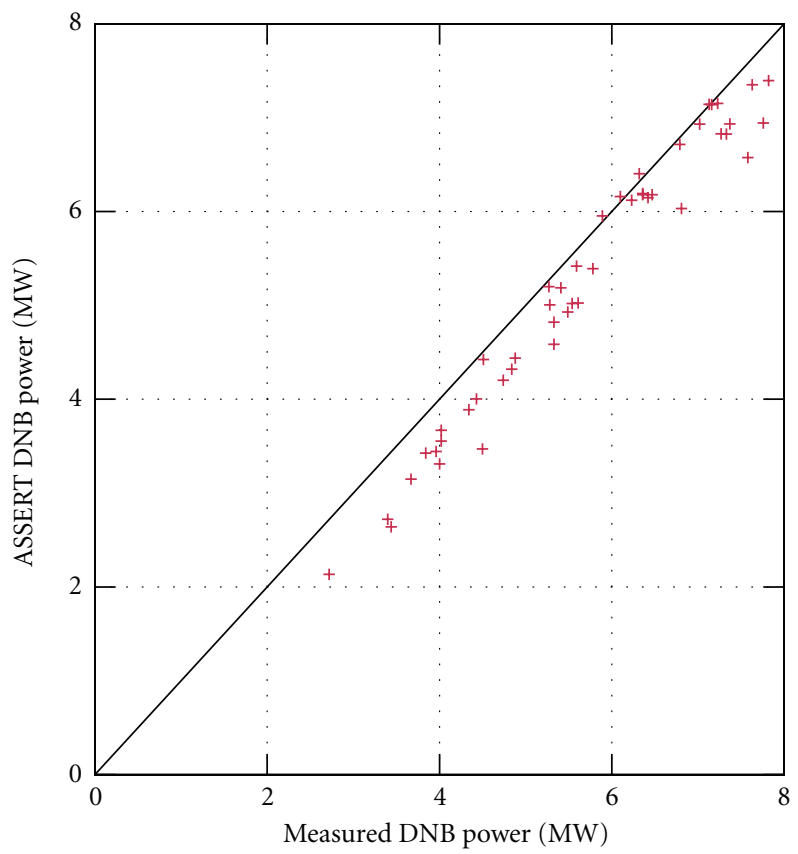

(c)

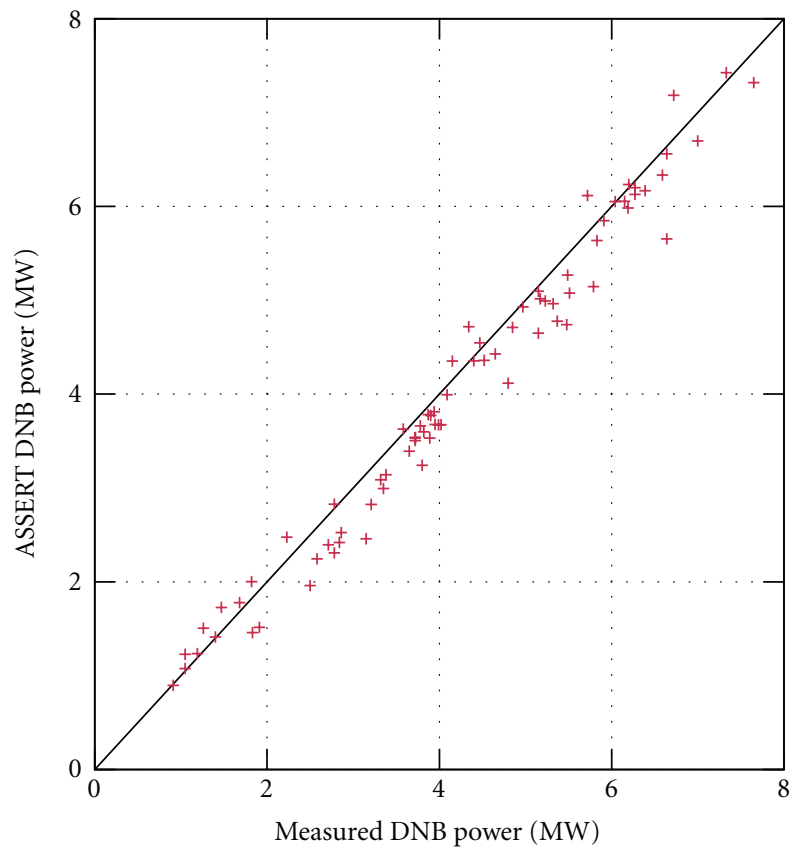

(b)

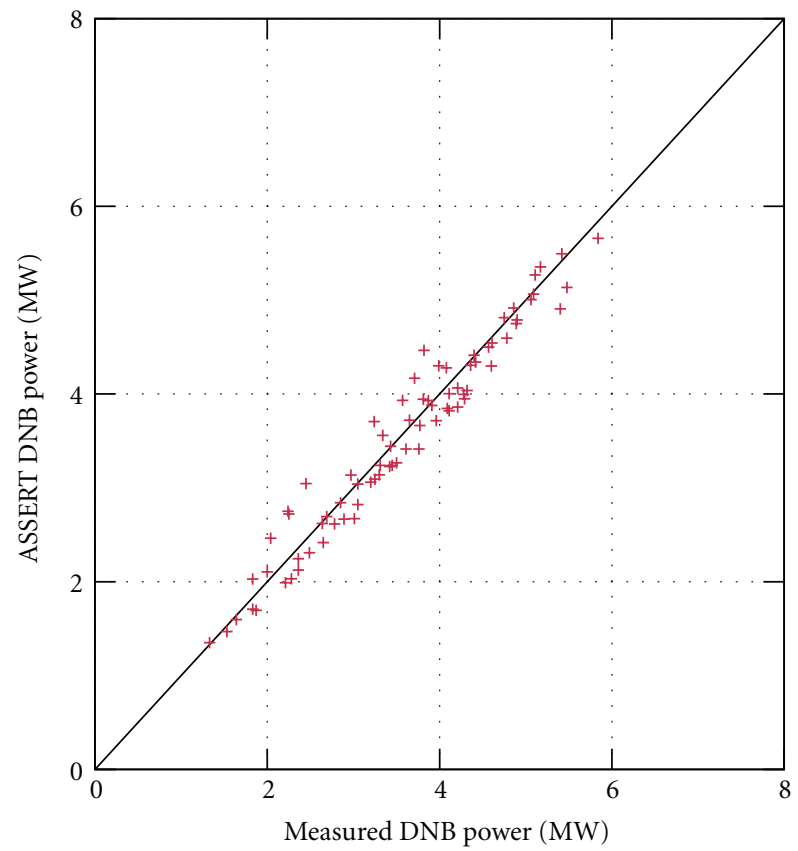

(d)

FIGURE 16: Steady state departure from nucleate boiling results for test series A0 (a), A2 (b), A3 (c), and A4 (d). The estimated uncertainty on the power measurements is $2 \sigma_{\exp }=2 \%$ and is not illustrated in the figure.

TABLE 6: Accuracy of steady state isolated subchannel void fraction predictions. The value of $1 \sigma$ is estimated to be \pm 0.03 .

\begin{tabular}{lccc}
\hline Geometry & $N_{\text {Points }}$ & Number of points where $\left|\epsilon_{\alpha}\right| \leq \pm \sigma_{\exp }$ (percent) & Number of points where $\left|\epsilon_{\alpha}\right| \leq \pm 2 \sigma_{\exp }($ percent) \\
\hline S1 (typical) & 43 & $19(44.2 \%)$ & $33(76.7 \%)$ \\
S2 (thimble) & 43 & $23(53.5 \%)$ & $36(83.7 \%)$ \\
S3 (side) & 20 & $5(25.0 \%)$ & $13(65.0 \%)$ \\
S4 (corner) & 20 & $9(45.0 \%)$ & $15(75.0 \%)$ \\
\hline Total & 126 & $56(44.4 \%)$ & $97(77.0 \%)$ \\
\hline
\end{tabular}




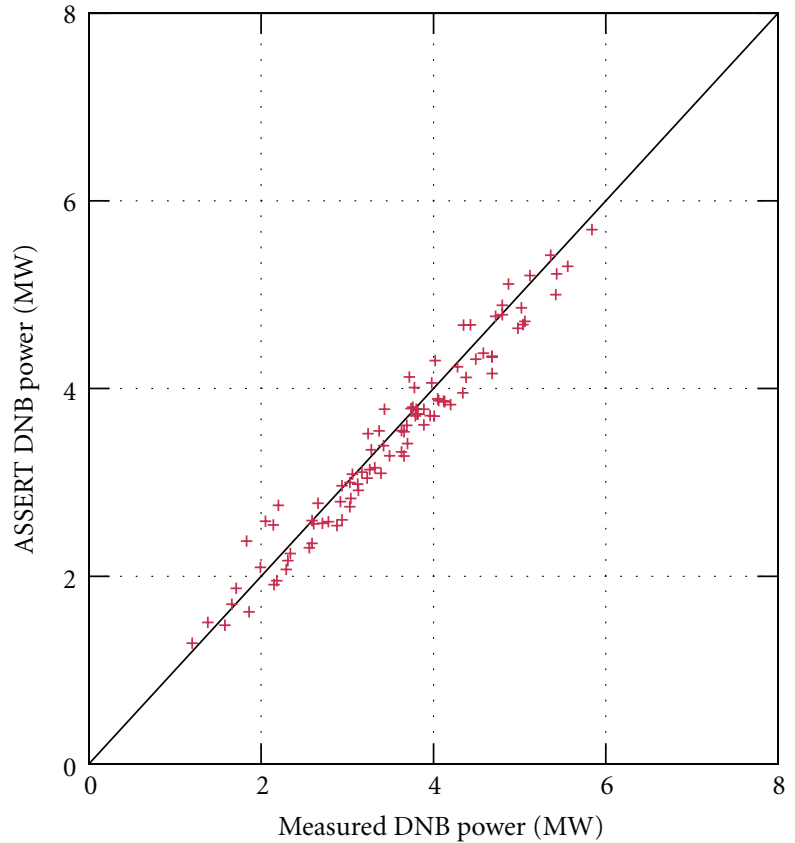

(a)

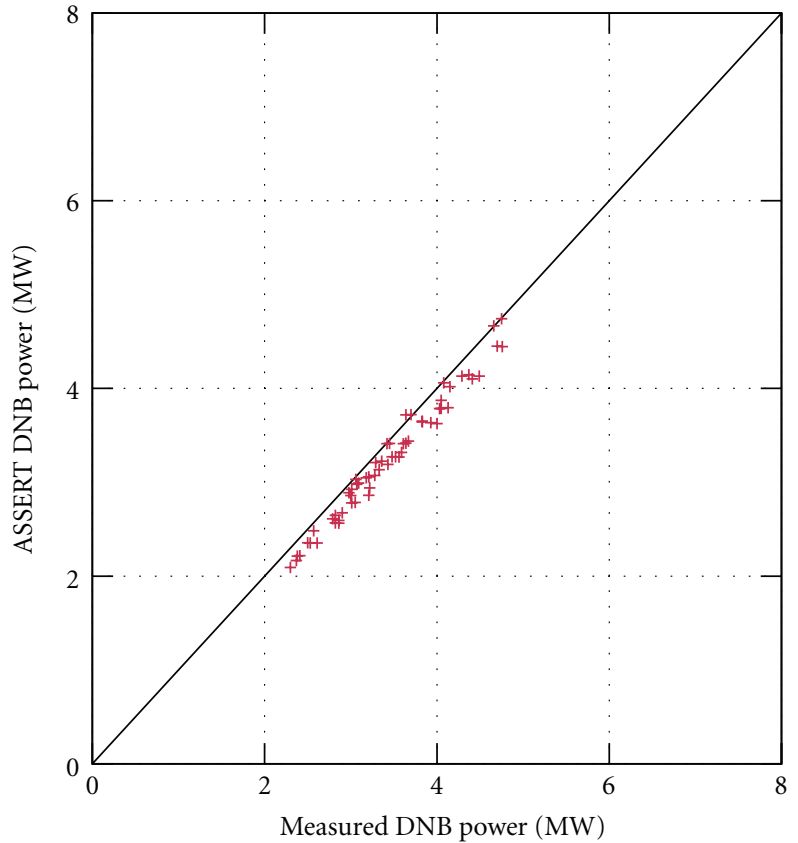

(b)

FIGURE 17: Steady state departure from nucleate boiling results for test series A8 (a) and A13 (b). The estimated uncertainty on the power measurements is $2 \sigma_{\exp }=2 \%$ and is not illustrated in the figure.

TABLE 7: Accuracy of steady state bundle void fraction predictions in the central 4 channels.

\begin{tabular}{lcccccccrrr}
\hline \multirow{2}{*}{ Series } & \multirow{2}{*}{$N_{\text {Cases }}$} & \multicolumn{3}{c}{ Lower $(z=2216 \mathrm{~mm})$} & \multicolumn{3}{c}{ Middle $(z=2669 \mathrm{~mm})$} & \multicolumn{3}{c}{ Upper $(z=3177 \mathrm{~mm})$} \\
& & $\bar{\epsilon}_{\alpha}$ & $\sigma_{\epsilon_{\alpha}}$ & $\epsilon_{\alpha, \mathrm{RMS}}$ & $\bar{\epsilon}_{\alpha}$ & $\sigma_{\epsilon_{\text {alpha }}}$ & $\epsilon_{\alpha, \mathrm{RMS}}$ & $\bar{\epsilon}_{\alpha}$ & $\sigma_{\epsilon_{\alpha}}$ & $\epsilon_{\alpha, \mathrm{RMS}}$ \\
\hline B5 & 74 & 0.0540 & 0.0395 & 0.0667 & 0.0337 & 0.0578 & 0.0666 & -0.0405 & 0.0534 & 0.0667 \\
B6 & 74 & 0.0642 & 0.0575 & 0.0860 & 0.0152 & 0.0650 & 0.0664 & -0.0491 & 0.0521 & 0.0714 \\
B7 & 74 & 0.1538 & 0.0497 & 0.1615 & 0.1130 & 0.0749 & 0.1353 & 0.0274 & 0.0581 & 0.0639 \\
\hline
\end{tabular}

reported ASSERT results [2]. Figure 11 illustrates the average void fraction error at each elevation for the B5 and B6 bundle tests, arranged by the system pressure. The plot suggests that there may be some tendency for the code to overpredict the void fraction as the pressure boundary condition is increased. The data for the B7 bundle is not illustrated as the larger magnitude of the over-prediction makes these trends less obvious.

A sensitivity study on the two-phase heat transfer correlation was also conducted using the cases from the B5 series of tests. Both the results from the Chen correlation, which is based on wall superheat [10], and the Lahey and Moody relationship, which is based on theory [11], are compared against the Ahmad equation. The steady state bundle void fraction predictions using these two relations are presented in Figure 12.

One of the major difficulties in predicting the behaviour of boiling flows is in determining the OSV point, and this is reflected by the variety of different treatments proposed by authors in literature. The Chen correlation postulates that the overall heat transfer coefficient is the sum of a single phase convective and a nucleate boiling component. Whereas the convective component is simply the DittusBoelter relationship from (8), the nucleate boiling portion is a function of many factors including the wall superheat [10]. When extended into the subcooled boiling regime, the Chen correlation is activated by the code as soon as the wall temperature exceeds the local saturation temperature at a computational node. In the PSBT experiments, the inlet subcooling ranged between 15 and $120^{\circ} \mathrm{C}$, and so in some of the cases with lower subcooling, the code would predict that the OSV point occurred in the node immediately downstream of the inlet. If the OSV point is prematurely predicted, then the superposition of the two heat transfer mechanisms causes the overall value of the coefficient to be overestimated, which in turn leads to the wall superheat being artificially suppressed. This ultimately means that the void profile with respect to heated length takes on a much gentler slope as compared to the predictions by the Ahmad correlation. The void results using the Chen correlation seem to support this as at the lower $\left(\bar{\epsilon}_{\alpha}=0.0453, \sigma_{\epsilon_{\alpha}}=0.0472\right)$ and middle $\left(\bar{\epsilon}_{\alpha}=-0.0146, \sigma_{\epsilon_{\alpha}}=0.0632\right)$ measurement 


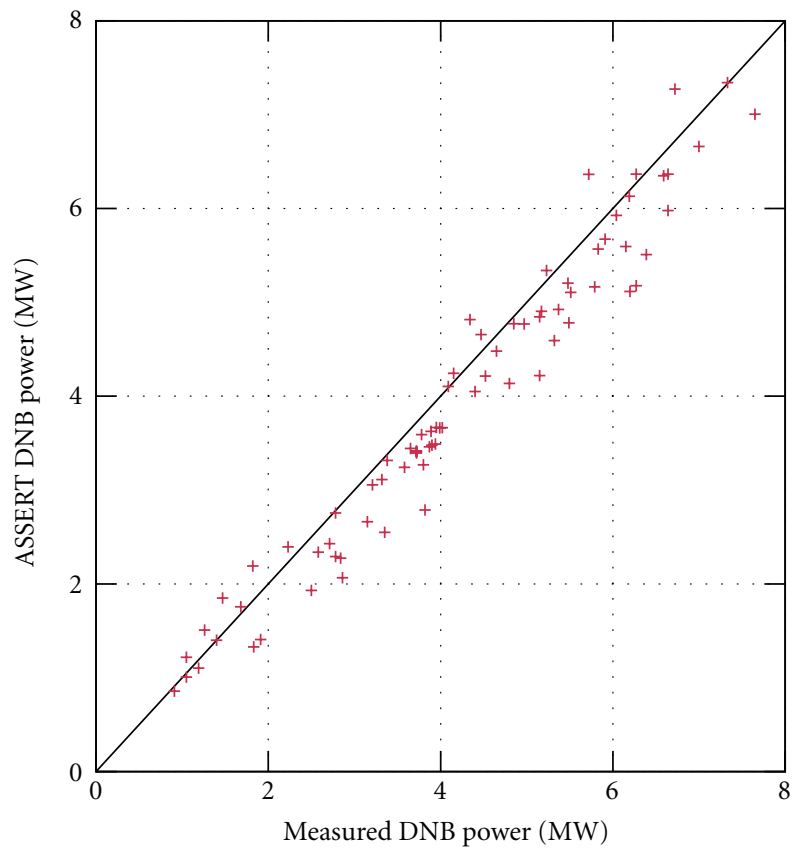

(a)

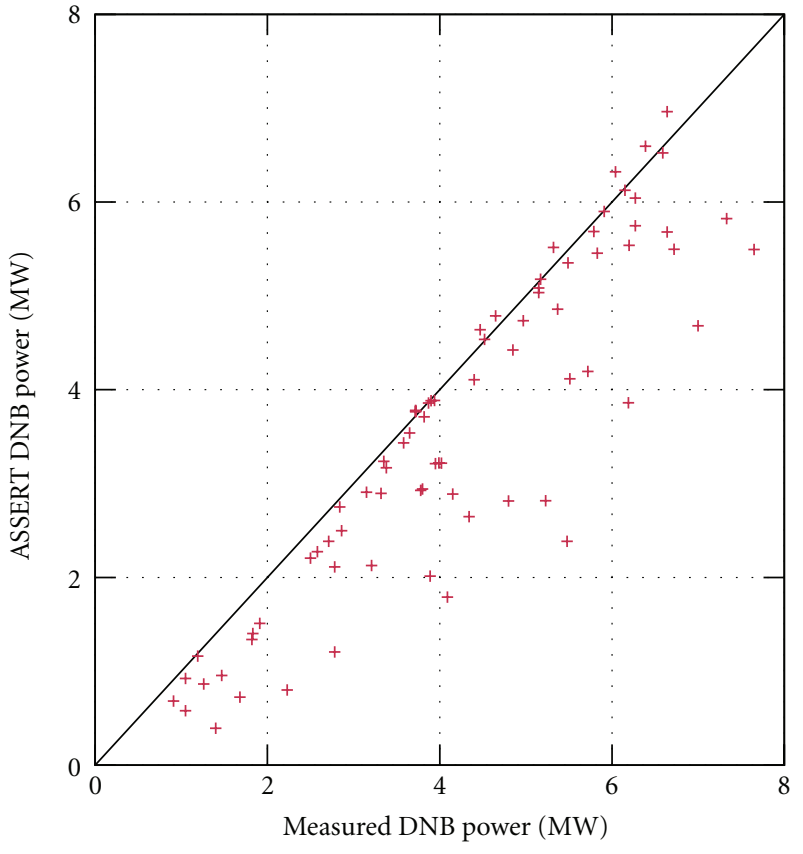

(b)

FIGURE 18: Steady state departure from nucleate boiling results for test series A2 using the Biasi correlation (a) and Weisman correlation (b). The estimated uncertainty on the power measurements is $2 \sigma_{\exp }=2 \%$ and is not illustrated in the figure.

elevations; they are better on average than what was predicted by the Ahmad correlation. However at the upper measurement elevation, the use of this correlation causes the code to severely underpredict the void $\left(\bar{\epsilon}_{\alpha}=-0.1112, \sigma_{\epsilon_{\alpha}}=\right.$ 0.0538).

In ASSERT, the Lahey correlation determines the OSV point using the same method as the Ahmad correlation; however, it is fit as a function of the subcooled enthalpy. The results are thus quantitatively similar to those predicted by the Ahmad correlation, although the magnitude varies slightly. At the lower elevation the Lahey correlation predicted the highest average deviation from the measured values $\left(\bar{\epsilon}_{\alpha}=0.0879, \sigma_{\epsilon_{\alpha}}=0.0455\right)$; however the results are better at the middle $\left(\bar{\epsilon}_{\alpha}=0.0602, \sigma_{\epsilon_{\alpha}}=0.0647\right)$ and upper $\left(\bar{\epsilon}_{\alpha}=-0.0251, \sigma_{\epsilon_{\alpha}}=0.0598\right)$ measurement points.

4.1.3. Transient Bundle. The transient bundle results are illustrated in Figures 13, 14, and 15. For each of the bundles, a power increase, flow reduction, and inlet temperature increase and depressurization transient was run for a total of 12 tests. General information about the boundary conditions for the tests are provided in Table 8, with a full description of the transient evolution available in [1]. The error trends in the transient portion of the benchmark were consistent with that of the steady state runs as ASSERT tended to overpredict the void fraction in the subcooled boiling region, while under-predicting at saturated conditions. This effect was observed to be more severe in the transients run on the $\mathrm{B} 5$ and $\mathrm{B} 6$ bundles than the B7 bundle. Additionally in all 12 of the cases, the code predicted void at each of the measurement elevations, whereas this was not reported in the experimental data.

While the magnitude of the void fraction predicted was incorrect, qualitatively the void development over time followed what was observed in the experiment in all cases except for the coolant temperature increase scenario. Some authors have proposed that the measurement location of the inlet temperature is far enough upstream of the heated section that it causes a 7-second time shift in the temperature profile [12]. Others have attributed this lag effect to the heat capacitance of the experimental apparatus [13]. In both cases, the authors found their predicted results time shifted from what was observed. The temperature shift has not been applied to the results of this study, and the rationale behind that decision is provided in the transient DNB section.

\subsection{Departure from Nucleate Boiling}

4.2.1. Steady State. The results for the steady state DNB portion of the benchmark are illustrated in Figures 16 and 17 while statistical data is listed in Table 9. The absolute DNB power error in Table 9 is defined as (21) in units of MW, whereas the relative DNB power error is defined as (22), as follows:

$$
\begin{gathered}
\epsilon_{P}=P_{\mathrm{DNB}, \mathrm{ASSERT}}-P_{\mathrm{DNB}, \mathrm{Exp}}, \\
\gamma_{P}=\frac{P_{\mathrm{DNB}, \mathrm{ASSERT}}}{P_{\mathrm{DNB}, \mathrm{Exp}}} .
\end{gathered}
$$




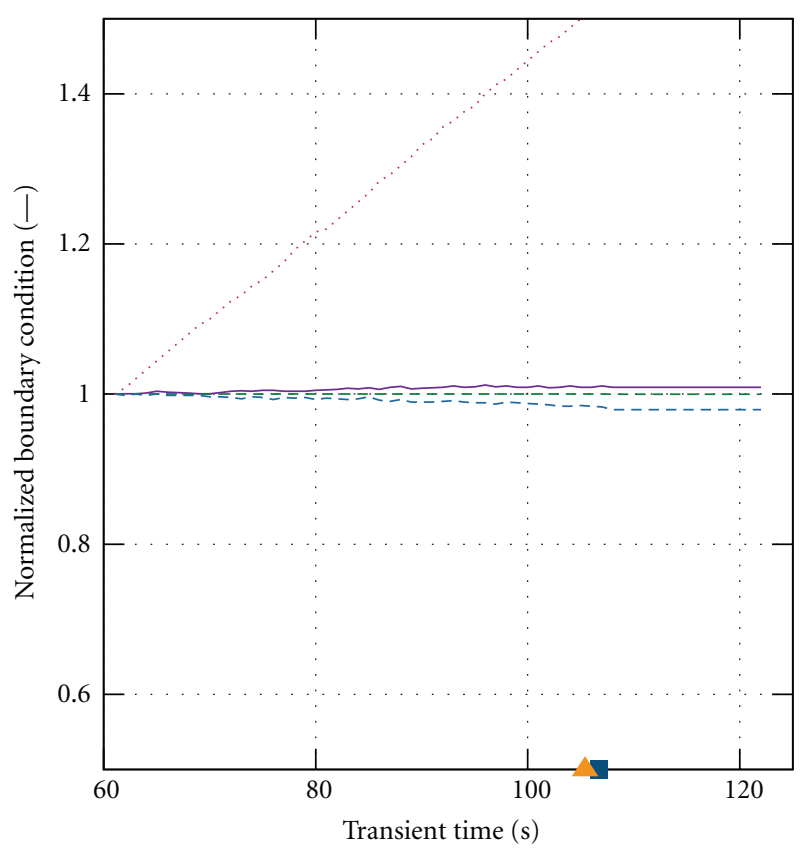

(a)

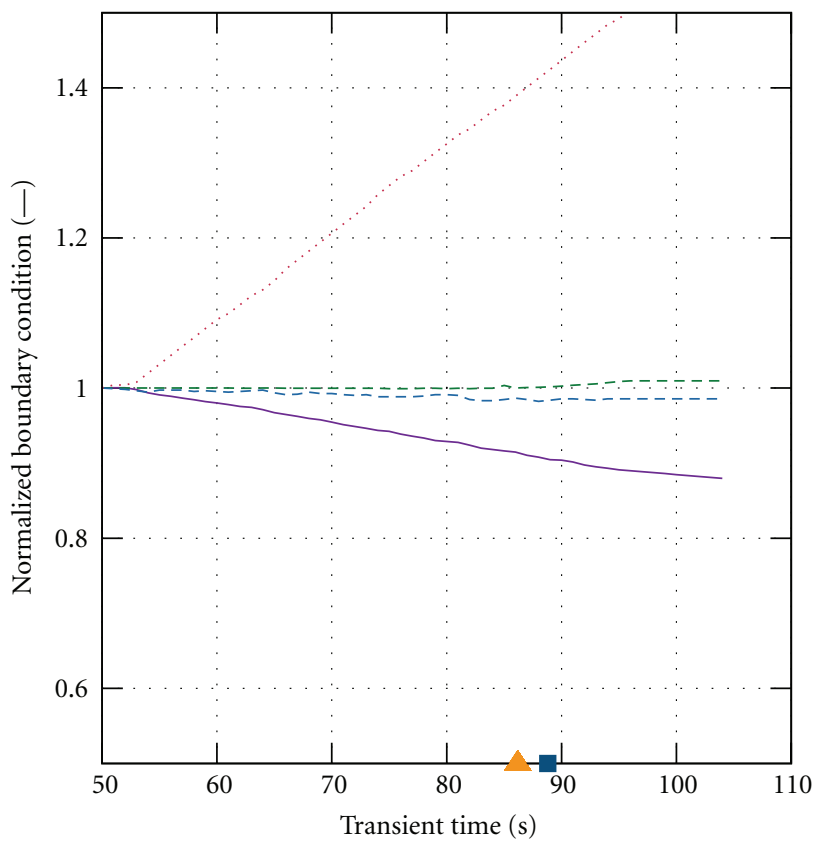
ASSERT DNB
- Exp. DNB
Power

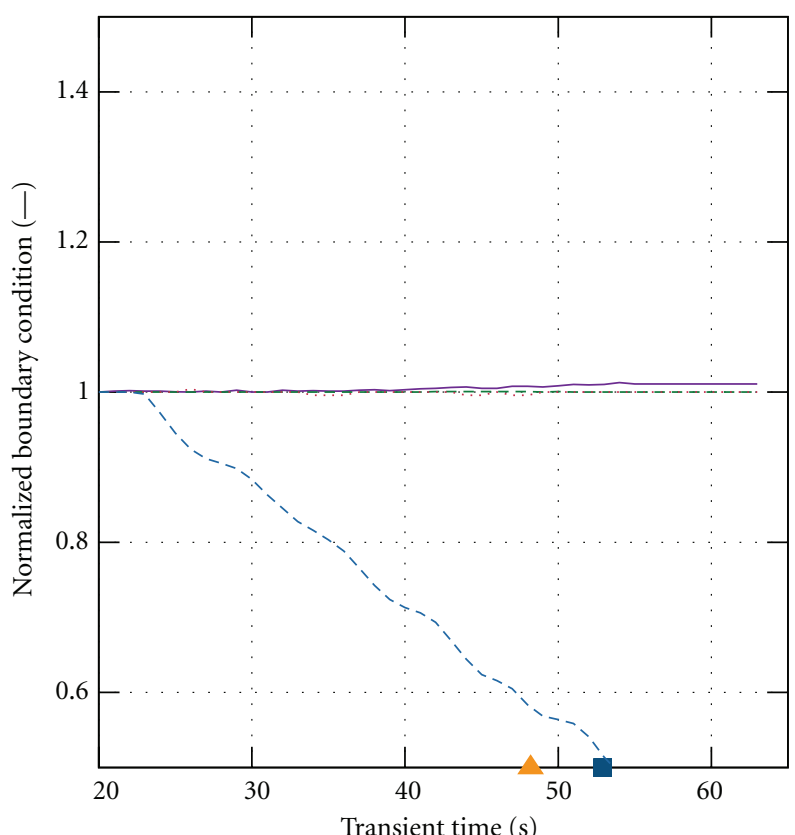

(b)

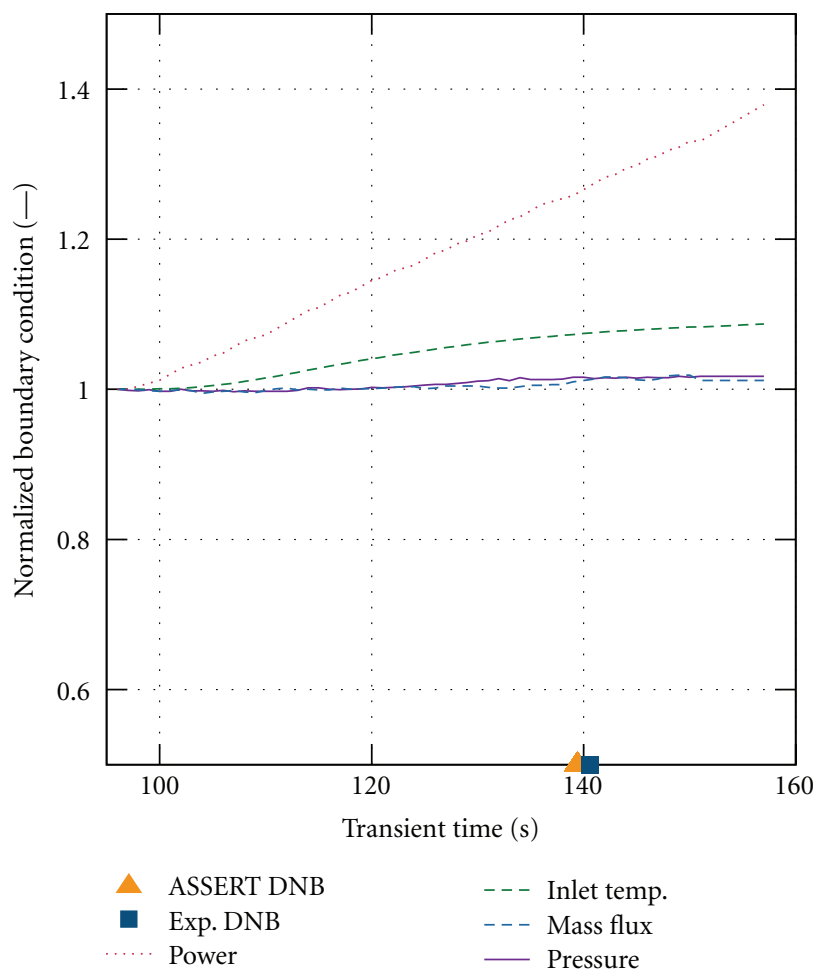

(d)

FIGURE 19: Transient departure from nucleate boiling results for test series A11. Power increase (a), flow reduction (b), depressurization (c), and inlet temperature increase (d). Estimated uncertainty on the power measurements is $2 \sigma_{\text {exp }}=2 \%$. 


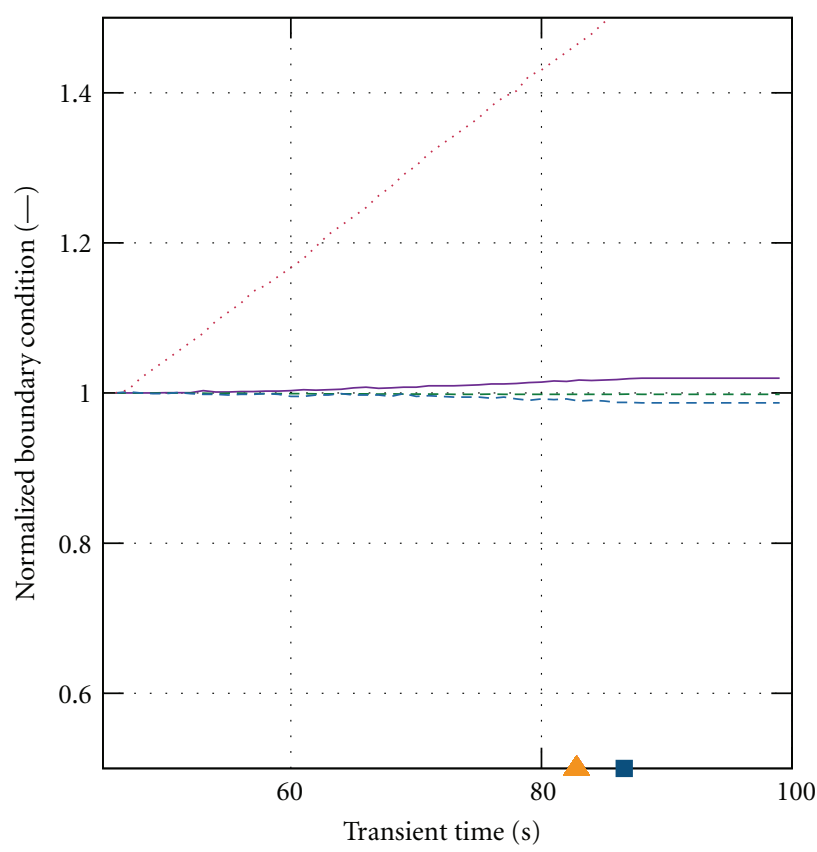

(a)

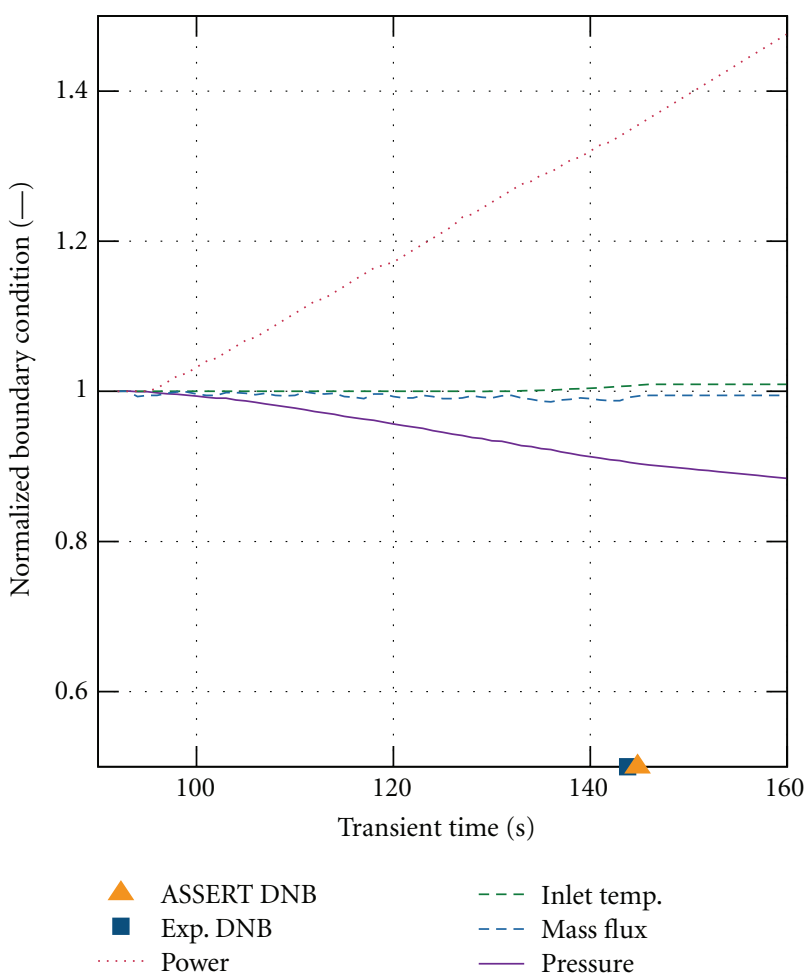

(c)

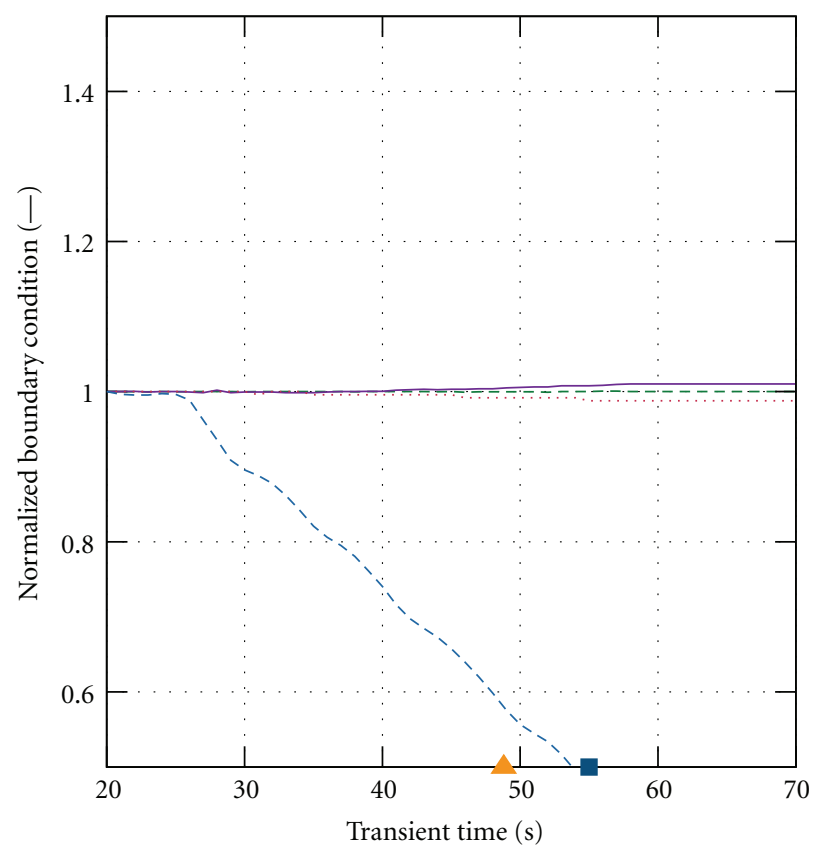

(b)

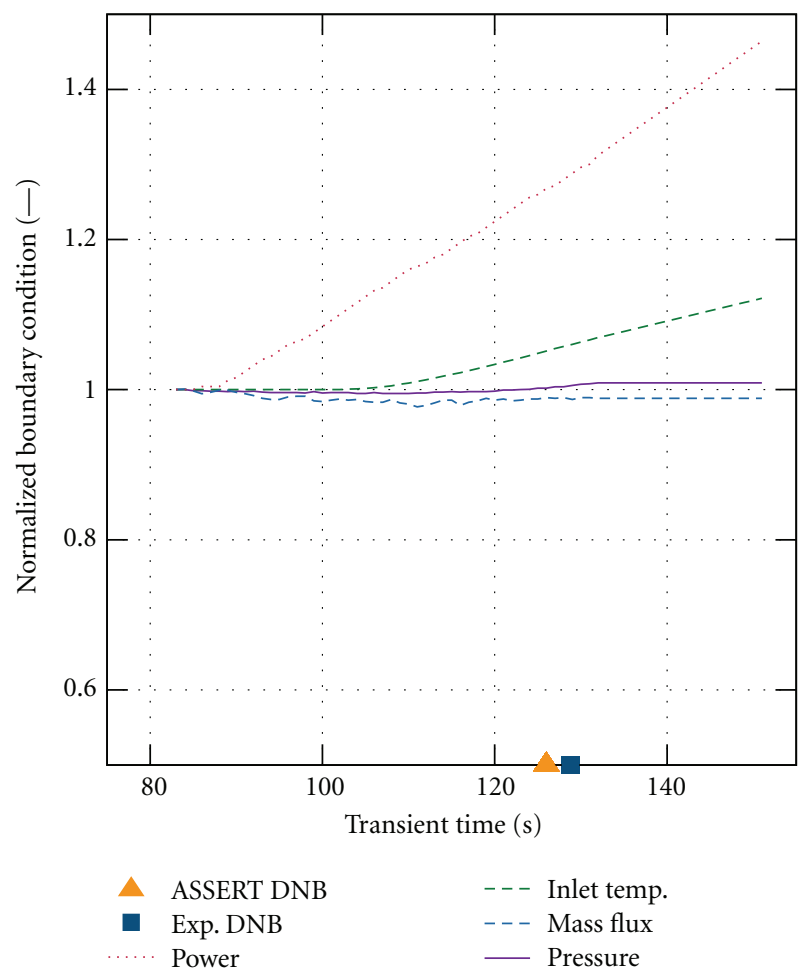

(d)

Figure 20: Transient departure from nucleate boiling results for test series A12. Power increase (a), flow reduction (b), depressurization (c), and inlet temperature increase (d). Estimated uncertainty on the power measurements is $2 \sigma_{\exp }=2 \%$.

Despite the deviation observed in some of the void results, the power at which DNB occurs is predicted very well since the void discrepancy is predominately at low vapour fractions where DNB is not likely to occur. With the exception of the A0 configuration, the code has a slight tendency to underpredict the power at which DNB occurs. This is most noticeable in the $6 \times 6$ bundle or the $\mathrm{A} 3$ configuration where the average predicted to measured DNB power was $\bar{\gamma}=0.930$.

An analysis was conducted on the steady state tests to ascertain the conditions where DNB was least accurately predicted. The 1995 Groeneveld lookup table supplies a 
TABLE 8: Initial conditions and maximum rates of change for each of the experiments.

\begin{tabular}{lcccc}
\hline & $\begin{array}{c}\text { Pressure } \\
(\mathrm{MPa})\end{array}$ & $\begin{array}{c}\text { Mass flux } \\
\left(\mathrm{Mg} / \mathrm{m}^{2} \mathrm{~s}\right)\end{array}$ & $\begin{array}{c}\text { Power } \\
(\mathrm{MW})\end{array}$ & $\begin{array}{c}\text { Inlet temperature } \\
\left({ }^{\circ} \mathrm{C}\right)\end{array}$ \\
\hline B5 & 15.0 & 3.3 & 2.3 & 300.1 \\
B6 & 15.4 & 3.3 & 2.6 & 288.5 \\
B7 & 15.5 & 3.3 & 2.5 & 291.5 \\
Max. rate & $-0.03 \mathrm{MPa} / \mathrm{s}$ & $-25 \% / \mathrm{s}$ & $+15 \% / \mathrm{s}$ & $1{ }^{\circ} \mathrm{C} / \mathrm{s}$ \\
\hline
\end{tabular}

TABLE 9: Accuracy of steady-state DNB bundle predictions.

\begin{tabular}{lcccccc}
\hline Test series & $N_{\text {Cases }}$ & $\bar{\epsilon}_{P}$ & $\sigma_{\epsilon_{P}}$ & $\epsilon_{P, \mathrm{RMS}}$ & $\bar{\gamma}_{P}$ & $\sigma_{\gamma_{P}}$ \\
\hline A0 & 70 & 0.336 & 0.216 & 0.398 & 1.080 & 0.043 \\
A2 & 76 & -0.180 & 0.270 & 0.325 & 0.960 & 0.084 \\
A3 & 57 & -0.370 & 0.300 & 0.475 & 0.930 & 0.064 \\
A4 & 76 & -0.038 & 0.242 & 0.243 & 0.993 & 0.080 \\
A8 & 93 & -0.079 & 0.230 & 0.320 & 0.984 & 0.080 \\
A13 & 60 & -0.184 & 0.102 & 0.210 & 0.945 & 0.030 \\
\hline
\end{tabular}

value for $\mathrm{CHF}$ as a function of the pressure, mass flux, and thermodynamic quality, and based on their analysis $88 \%$ of the data will fall within $\pm 10 \%$ of the predicted value [3] Using this as the basis of the current assessment, Tables 10 and 11 list the number of cases in each series of tests which fulfil this criteria and are arranged by mass flux and pressure, respectively.

The results suggest that either the code or the lookup table are less accurate at lower mass fluxes as only 18 of the 32 cases $(56.3 \%)$ where $G<1.0 \mathrm{Mg} / \mathrm{m}^{2}$ s fell within $\pm 10 \%$ of the experimental value-this is compared to the $2.0 \leq$ $G<3.0$ range where 79 of 92 tests $(85.9 \%)$ met this criteria. When the cases are split by pressure, it is more difficult to derive conclusions since PSBT tests were run at many different pressures. Most of the cases were run at approximately $15.0 \mathrm{MPa}$, and the data indicates that $83.6 \%$ of the predictions met the accuracy criteria which is close to what would be expected.

During the development of the 1995 Groeneveld CHF look up table, the authors noted that there were several discontinuities in the data which they attributed to experimental uncertainty and second-order effects [3]. At the time, it was understood that there was no physical basis for these discontinuities, and so the data in the table was smoothed with respect to pressure, mass flux, and thermodynamic quality [3]. However in the 2006 version of the lookup table, some of this smoothing was removed since it was determined that the discontinuities were consistent with evidence supporting a sharp drop-off in the CHF with respect to quality under very specific pressure and flow conditions [14]. This drop-off is termed the Limited Quality Region (LQR), and Groeneveld suggests that it may be the transition between entrainment and deposition based dryout [15].

A closer examination of the 14 PSBT DNB cases in the low mass flux $\left(G<1.0 \mathrm{Mg} / \mathrm{m}^{2}\right)$ region which fell outside the $\pm 10 \%$ bounds found that almost all were over-predicted by between 15 and $30 \%$ which is substantially beyond what would be expected given the accuracy of the other cases in the benchmark. These cases were run at mass fluxes of $0.3<G<0.6 \mathrm{Mg} / \mathrm{m}^{2}$ across all benchmark pressures, with DNB being predicted at $X_{\mathrm{th}}>0.75$. Comparing the boundary conditions used in these outlying cases with the 2006 lookup table shows that every single one of these tests fell either in an area identified as part of the LQR, or in a cell immediately adjacent to it. If the cases falling in the LQR are neglected from the analysis, then the DNB prediction accuracy across all bundles where $G<1.0 \mathrm{Mg} / \mathrm{m}^{2}$ improves to 18 of 24 cases falling within $\pm 10 \%$ of the experimental value which is more consistent with the results at higher mass fluxes.

While this is only a rudimentary analysis, this seems to suggest that the error may be at least partially attributed to the smoothing in the 1995 version of the lookup table which was used in the code. This result however is contrary to the conclusions of [15], who believes that the LQR phenomena are suppressed in bundles due to the mixing vanes and spacers. This discrepancy suggests that further studies are required in establishing the effects of bundle appendages or spacer grids on the limiting quality phenomena.

A sensitivity study was also conducted in order to assess the different methods of predicting the DNB power, with both the Biasi and the Weisman and Pei correlations being tested against the $\mathrm{A} 2$ series of measurements. The results of these tests are illustrated in Figure 18 which shows a tendency for both correlations to underestimate the point at which DNB occurs, with the Biasi correlation having the better overall average of the two $\left(\bar{\gamma}_{P, \text { Biasi }}=\right.$ 0.9379 versus $\left.\bar{\gamma}_{P, \text { Weisman }}=0.8307\right)$. The Weisman and Pei correlation seemed to have particular difficulty in predicting the cases where the system pressure was below 9.8 MPa, with the average predicted to measured power ratio being $\bar{\gamma}_{P, \text { Weisman, } p<9.8 \mathrm{MPa}}=0.6121$ among these cases.

4.2.2. Transient. In this portion of the benchmark, power increase, flow reduction, depressurization, and inlet temperature transients were run with both the A11 and A12 bundle configurations. Initial boundary conditions for these transients are listed in Table 12 while the time at which each bundle reached DNB in the experiment and ASSERT is illustrated in Figures 19 and 20. The power profile and geometry of bundles A11 and A12 are identical to bundles A4 and $A 8$ used in the steady state portion, and since the average prediction error was the smallest in those two series of tests, the transient portion was generally very well predicted. The code predicts the DNB time early in 7 of the 8 tests, which is consistent with the observation that ASSERT has a slight underestimation of the DNB power in the A4 and A8 steady state cases. In the flow reduction transients the DNB time is predicted 4.7 and 6.2 seconds early for the A11 and A12 bundles, respectively, and this represents the largest magnitude of error.

As indicated in Table 12 the error in the DNB time predicted in the inlet temperature increase scenario is consistent with the results obtained by the other transients. 
TABLE 10: Number of cases where ASSERT steady state DNB predictions fell within $\pm 10 \%$ of measured value, arranged by mass flux.

\begin{tabular}{lccccccc}
\hline Mass flux $\left(\mathrm{Mg} / \mathrm{m}^{2} \mathrm{~s}\right)$ & $\mathrm{A} 0$ & $\mathrm{~A} 2$ & $\mathrm{~A} 3$ & $\mathrm{~A} 4$ & $\mathrm{~A} 8$ & A13 & - \\
\hline$G<1$ & - & $7 / 12$ & - & $5 / 10$ & $6 / 10$ & $18 / 32$ \\
$1 \leq G<2$ & $8 / 10$ & $7 / 12$ & $5 / 10$ & $16 / 21$ & $17 / 22$ & $4 / 4$ & $57 / 79$ \\
$2 \leq G<3$ & $6 / 9$ & $8 / 10$ & $9 / 15$ & $6 / 6$ & $16 / 16$ & $34 / 36$ \\
$3 \leq G<4$ & $28 / 41$ & $26 / 33$ & $18 / 24$ & $31 / 32$ & $34 / 38$ & $20 / 20$ & $157 / 188$ \\
$4 \leq G$ & $6 / 10$ & $7 / 9$ & $6 / 8$ & $7 / 7$ & $7 / 7$ & - & $33 / 41$ \\
\hline Total & $48 / 70$ & $55 / 76$ & $38 / 57$ & $65 / 76$ & $80 / 93$ & $58 / 60$ & $344 / 432$ \\
\hline
\end{tabular}

TABLE 11: Number of cases where ASSERT steady state DNB predictions fell within $\pm 10 \%$ of measured value, arranged by pressure.

\begin{tabular}{lccccccc}
\hline Pressure $(\mathrm{MPa})$ & A0 & A2 & A3 & A4 & A8 & A13 & Total \\
\hline $4.7 \leq p<5.2$ & - & $12 / 14$ & - & $0 / 4$ & $6 / 8$ & - & $18 / 26$ \\
$7.3 \leq p<7.8$ & - & $4 / 6$ & - & $5 / 9$ & $5 / 9$ & $14 / 24$ \\
$9.7 \leq p<10.2$ & $12 / 15$ & $9 / 16$ & $9 / 12$ & $14 / 15$ & $16 / 18$ & - & $60 / 76$ \\
$12.1 \leq p<12.6$ & $11 / 14$ & $5 / 7$ & $6 / 11$ & $12 / 13$ & $15 / 16$ & $4 / 4$ & $4 / 4$ \\
$13.1 \leq p<13.6$ & - & - & - & - & - & $4 / 65$ \\
$14.6 \leq p<15.1$ & $18 / 26$ & $17 / 23$ & $14 / 21$ & $21 / 21$ & $21 / 24$ & $42 / 44$ & $133 / 159$ \\
$15.3 \leq p<15.8$ & $2 / 2$ & $3 / 3$ & $1 / 1$ & $2 / 2$ & $4 / 4$ & $4 / 4$ & $16 / 16$ \\
$16.3 \leq p<16.8$ & $5 / 13$ & $5 / 7$ & $8 / 12$ & $11 / 12$ & $13 / 14$ & $4 / 4$ & $46 / 62$ \\
\hline Total & $48 / 70$ & $55 / 76$ & $38 / 57$ & $65 / 76$ & $80 / 93$ & $58 / 60$ \\
\hline
\end{tabular}

This is something which was not expected since there has been much discussion on applying a time shift on the results of the void inlet temperature increase transients. If inlet temperature measurements were "lagged", it would mean that any change in the temperature reported would not propagate to the heated section until after a 6 - or 7-second delay has elapsed. This implies that true inlet temperature at the reported DNB time is lower and should be roughly the value which was recorded 7 seconds earlier. In the A11 transient this corresponds to about a $-2.5^{\circ} \mathrm{C}$ discrepancy, whereas it is approximately $-6.1^{\circ} \mathrm{C}$ in the $\mathrm{A} 12$ case-which is significant. It would also mean that if ASSERT is reporting that DNB occurs at approximately the same time as the experiment, then the result represents a much larger underprediction than what was observed in the other transients of the series which all have very similar initial conditions.

On average while the $\mathrm{A} 4$ and $\mathrm{A} 8$ steady state $\mathrm{DNB}$ powers were predicted to within $2 \%$ of the measured power, there is a scatter of $\sigma_{\gamma_{P}}=0.08$, meaning that in the ASSERT transient results presented, it is possible that the temperature lag does exist; however its effect may be obscured by the natural scatter of the code. Ultimately, the exact nature of the time delay is inconclusive, which is why in this study, the reported results for both the void fraction and DNB inlet temperature increase transients have been left unshifted.

\section{Conclusions}

Predictions from ASSERT-PV V3R1 were compared against data from the OECD/NEA PSBT benchmark. Although the single subchannel void tests were predicted well, in the bundle tests the lateral momentum induced by the mixing vanes and spacer grids exceeds the default values of the
Carlucci mixing correlation which were derived for PHWR designs, and so some adjustments to the mixing coefficients were required. Specifically, the coefficients for the magnitude of the mixing enhancement due to a flow obstruction and the decay length were adjusted based on an estimation of loss coefficient or " $k$-factor" at each subchannel, a set of fluid temperature measurements, and results reported in literature.

A comparison of the simulated values against the experimental data showed good agreement under nucleate boiling conditions, although the code demonstrated a tendency to over-predict the void in the subcooled regime. Changing the two-phase heat transfer correlation used did affect the steady state results; however it was determined that the default correlation of Ahmad was the most accurate-despite being used outside its recommended range. The error in the transient results was qualitatively similar to the steady state cases, with void overpredictions occurring in the subcooled regions.

Good agreement was obtained in the steady state DNB portion of the benchmark, albeit the code was observed to slightly under-predict the power. A decline in the accuracy of the predictions was also observed under boundary conditions with lower mass fluxes and pressures. This was attributed to the boundary conditions falling within the limiting quality region which is not represented in the $\mathrm{CHF}$ lookup table used in the code. In the transient tests, the code predicted DNB occurring within 3 seconds of the experimental result, except during the flow reduction tests. The Biasi and Weisman DNB correlations were also tested against the Groeveneld lookup table and did not yield results which were more accurate. The Biasi correlation in particular had difficulty predicting the DNB power at lower pressures. 
TABLE 12: Transient initial conditions, predicted and measured DNB times.

\begin{tabular}{|c|c|c|c|c|c|c|c|}
\hline Bundle & Transient & Power (MW) & Mass flux $\left(\mathrm{Mg} / \mathrm{m}^{2} \mathrm{~s}\right)$ & Pressure $(\mathrm{MPa})$ & Inlet temperature $\left({ }^{\circ} \mathrm{C}\right)$ & $t_{\mathrm{DNB}, \exp }(\mathrm{s})$ & $t_{\mathrm{DNB}, \operatorname{sim}}(\mathrm{s})$ \\
\hline \multirow{4}{*}{ A11 } & Power increase & 2.50 & 3.11 & 15.32 & 291.0 & 106.7 & 105.4 \\
\hline & Flow reduction & 2.50 & 3.11 & 15.31 & 293.1 & 52.9 & 48.2 \\
\hline & Depressurization & 2.52 & 3.13 & 15.33 & 291.7 & 88.8 & 86.2 \\
\hline & Temp. increase & 2.48 & 3.07 & 15.16 & 291.6 & 140.6 & 139.4 \\
\hline \multirow{4}{*}{ A12 } & Power increase & 2.51 & 3.17 & 15.31 & 291.3 & 86.6 & 82.8 \\
\hline & Flow reduction & 2.51 & 3.25 & 15.33 & 292.5 & 55.0 & 48.8 \\
\hline & Depressurization & 2.50 & 3.17 & 15.32 & 290.6 & 143.8 & 144.8 \\
\hline & Temp. increase & 2.50 & 3.16 & 15.28 & 291.2 & 128.8 & 126.0 \\
\hline
\end{tabular}

\section{Nomenclature}

A: Subchannel cross-sectional area

$d_{\text {hyd }}:$ Hydraulic diameter

$d_{\text {rod }}$ : Rod diameter

$f$ : Friction factor

$g: \quad$ Gravitational acceleration

G: Mass flux

$h_{f}$ : Liquid enthalpy

$h_{f g}:$ Latent heat of vaporization

$h_{g}$ : Vapour enthalpy

$H$ : Heat transfer coefficient

$k$ : Pressure loss coefficient

$K_{f}$ : Bulk fluid thermal conductivity

$P$ : $\quad$ Power

$p: \quad$ Pressure

$q^{\prime \prime}$ : Heat flux

S: $\quad$ Gap width

$t$ : Time

$\vec{u}: \quad$ Axial velocity

$\vec{v}: \quad$ Lateral velocity

$W_{k}$ : Lateral mass flow rate to subchannel $k$

$W^{\prime}$ : Intersubchannel turbulent mixing rate

$\Delta x:$ Axial node spacing

$X: \quad$ Mass quality

$X_{\text {th }}$ : Thermodynamic quality.

\section{Greek Symbols}

$\alpha: \quad$ Void fraction

$\delta$ : Roughness height

$\epsilon_{P}:$ Absolute error

$\gamma_{P}:$ Relative error

$\mu$ : Viscosity

$\Phi_{2}$ : Two-phase multiplier

$\rho_{f}$ : Fluid density

$\rho_{g}$ : Vapour density

$\sigma_{\text {exp }}$ : Experimental uncertainty.

\section{Dimensionless Numbers}

Fr: Froude number

Re: Reynolds number

Pr: Prandtl number

We: Weber number.

\section{Acknowledgments}

The authors would like to thank Dr. Yanfei Rao (AECL Chalk River Labs) for his support and advice on the ASSERT code, as well Mr. Adam Rubin and Dr. Maria Avramova (Penn State University) for their tireless efforts in organizing and coordinating the PSBT benchmark activities. The authors also would like to acknowledge AECL for the use of the code, and the financial support of NSERC and UNENE.

\section{References}

[1] A. Rubin, A. Schoedel, M. Avramova, H. Utsuno, S. Bajorek, and A. Valazquez-Lozada, "OECD/NRC benchmark based on NUPEC PWR subchannel and bundle tests (PSBT)," Tech. Rep., OECD/NEA, 2010.

[2] S. Y. Ahmad, "Axial distribution of bulk temperature and void fraction in a heated channel with inlet subcooling," Journal of Heat Transfer, vol. 92, no. 4, pp. 595-609, 1970.

[3] D. C. Groeneveld, L. K. H. Leung, P. L. Kirillov et al., "The 1995 look-up table for critical heat flux in tubes," Nuclear Engineering and Design, vol. 163, no. 1-2, pp. 1-23, 1996.

[4] L. N. Carlucci, N. Hammouda, and D. S. Rowe, "Two-phase turbulent mixing and buoyancy drift in rod bundles," Nuclear Engineering and Design, vol. 227, no. 1, pp. 65-84, 2004.

[5] M. Glück, "Validation of the sub-channel code F-COBRA-TF. Part I. Recalculation of single-phase and two-phase pressure loss measurements," Nuclear Engineering and Design, vol. 238, no. 9, pp. 2308-2316, 2008.

[6] I. E. Idelchik, Handbook of Hydraulic Resistance, Hemisphere Publishing Corporation, 2nd edition, 1976.

[7] H. L. McClusky, M. V. Holloway, D. E. Beasley, and M. E. Conner, "Development of swirling flow in a rod bundle subchannel," Journal of Fluids Engineering, vol. 124, no. 3, pp. 747-755, 2002.

[8] H. Gabriel and M. Glück, "Prediction of void fraction for PWR and BWR conditions with the subchannel code F-COBRA-TF," Nuclear Engineering and Design, vol. 241, no. 9, pp. 3952-3966, 2011.

[9] M. Valette, "Subchannel and rod bundle PSBT simulations with cathare 3," in Proceedings of the International Topical Meeting on Nuclear Reactor Thermalhydraulics (NURETH'11), 2011.

[10] J. G. Collier and J. R. Thome, Convective Boiling and Condensation, Oxford University Press, New York, NY, USA, 3rd edition, 1994. 
[11] R. T. Lahey Jr. and F. J. Moody, The Thermal Hydraulics of a Boiling Water Nuclear Reactor, American Nuclear Society, 2rd edition, 1993.

[12] T. W. Kim and A. Manera, "Prediction of void fraction in a subchannel and bundle geometry with FLICA4 and TRACE," in Proceedings of the International Topical Meeting on Nuclear Reactor Thermalhydraulics (NURETH'11), 2011.

[13] M. Avramova, A. Velazquez-Lozada, and A. Rubin, "Comparative analysis of CTF and TRACE thermalhydraulics codes using OECD/NEA PSBT benchmark void distribution database," in Proceedings of the International Topical Meeting on Nuclear Reactor Thermalhydraulics (NURETH'11), 2011.

[14] D. C. Groeneveld, J. Q. Shan, A. Z. Vasić et al., "The 2006 CHF look-up table," Nuclear Engineering and Design, vol. 237, no. 15-17, pp. 1909-1922, 2007.

[15] D. C. Groeneveld, "Anomalies and other concerns related to the critical heat flux," Nuclear Engineering and Design, vol. 241, no. 11, pp. 4604-4611, 2011. 

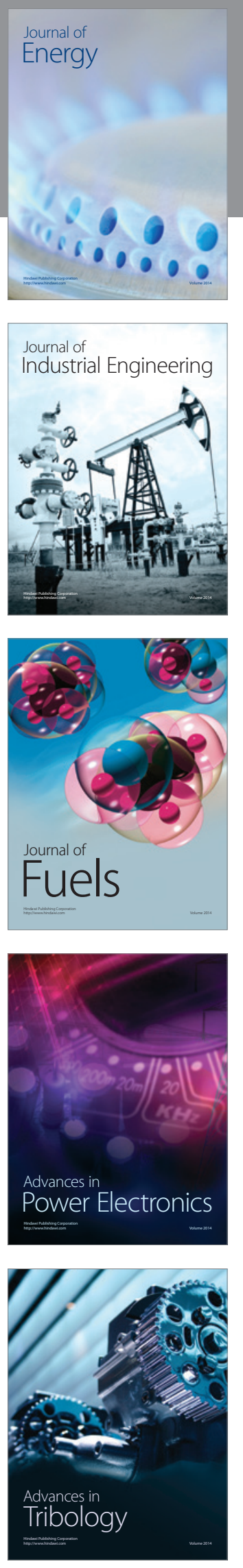
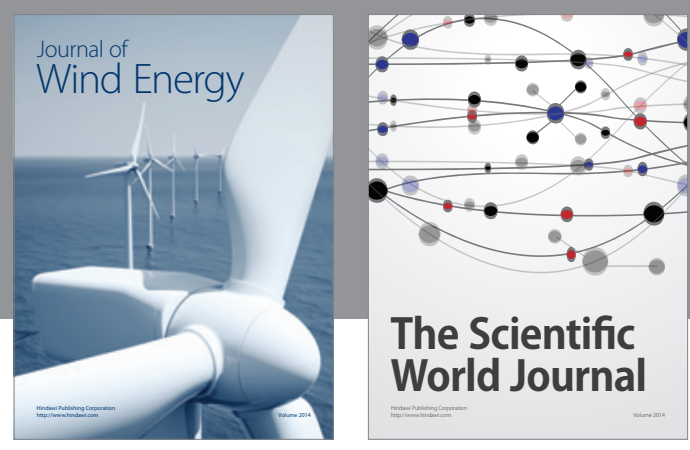

The Scientific World Journal

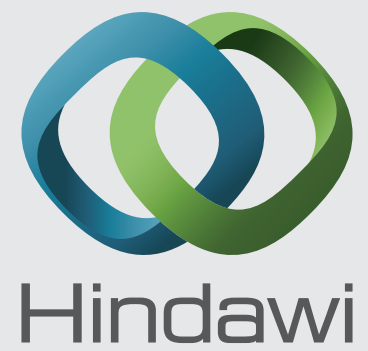

Submit your manuscripts at http://www.hindawi.com
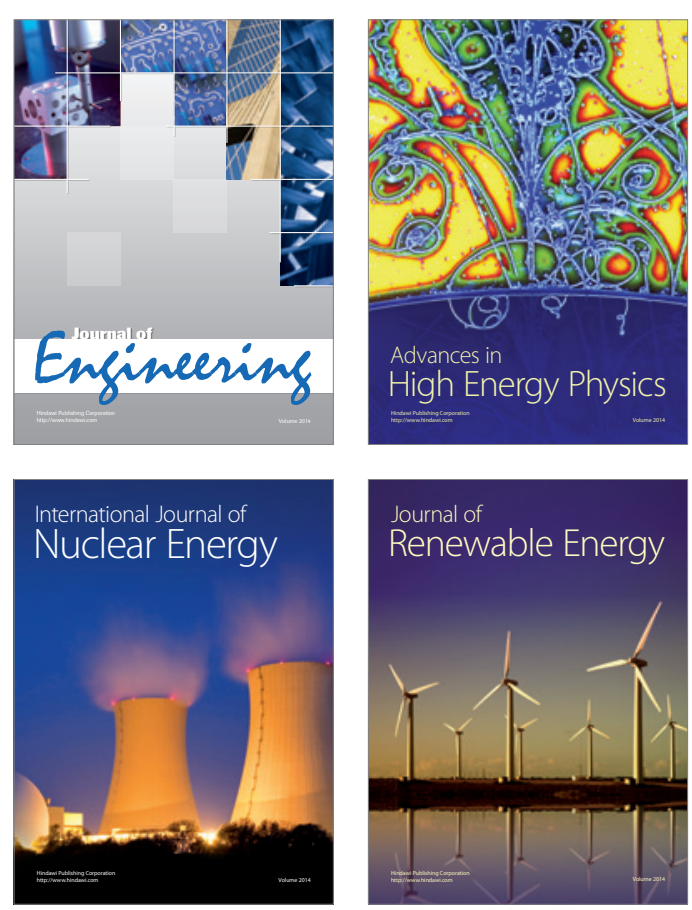

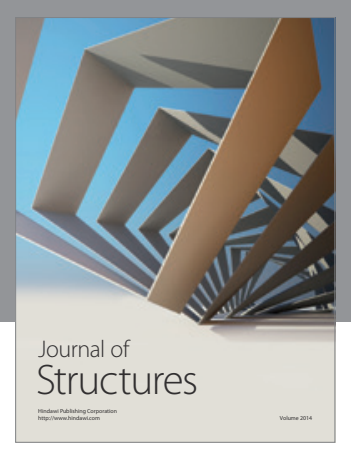

Rotating
Mechinery
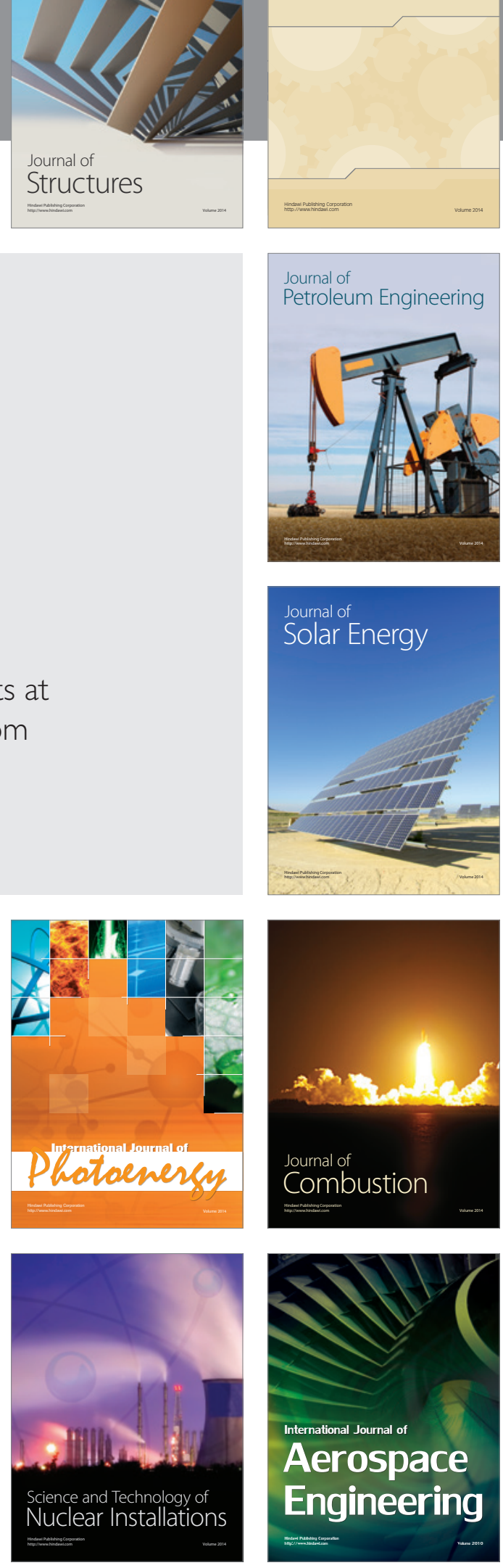